\title{
Integrated Analysis of IncRNA-associated ceRNA Network Identifies Prognostic IncRNAs in Bladder Cancer Based on Whole Transcriptome Sequencing and TCGA Database
}

\section{Shiwei Xiao}

Kunming Medical University Second Hospital

Yigang Zuo

Kunming Medical University Second Hospital

\section{Yinglong Huang}

Kunming Medical University Second Hospital

Yanan Li

Guizhou University Of Traditional Chinese Medicine

\section{Dongbo Yuan}

: Guizhou Provincial People's Hospital

\section{Mingxia Ding}

Kunming Medical University Second Hospital

\section{Haifeng Wang}

Kunming Medical University Second Hospital

Jiansong Wang ( $\sim$ wangjiansong@kmmu.edu.cn )

Kunming College: Kunming University https://orcid.org/0000-0001-5451-5358

\section{Primary research}

Keywords: Bladder cancer, Whole transcriptome sequencing, Nomogram, Prognosis signature, Bioinformatics analysis

Posted Date: July 7th, 2021

DOI: https://doi.org/10.21203/rs.3.rs-663356/v1

License: @ (i) This work is licensed under a Creative Commons Attribution 4.0 International License. Read Full License 


\section{Abstract}

\section{Background}

Bladder cancer $(\mathrm{BC})$ is a serious urinary tract malignancy with high incidences and deaths. Here, we aim to explore the OSrelated IncRNAs and mRNAs, and constructed a reliable predicting model for accurately predict BC prognosis.

Methods

3 matched BC tumor samples and adjacent normal samples were processed by whole transcriptome sequencing. Differentially expressed IncRNAs and mRNAs (DE-IncRNAs and DE-mRNAs) were identified with the thresholds $\mid \log 2$ (FC) $\mid>2$ and $p$ value $<0.05$ using DEGseq2 R package. Meantime, $408 \mathrm{BC}$ samples and 19 normal samples were downloaded from TCGA database. And DE-IncRNAs and DE-mRNAs were screened with thresholds $\| \log 2(\mathrm{FC}) \mid>0.5$ and $p$ value $<0.05$. The DE-IncRNAs and DEmRNAs were overlapped between RNA-sequencing data and TCGA data. Then, overall survival (OS)-related DE-IncRNAs and DE-mRNAs were screened and a prognostic gene signature and risk model were constructed using Univariate Cox and stepwise multiple regression analysis. Risk score was calculated based on prognostic gene signature. The independent risk factors were identified with incorporation into clinical risk factors using Univariate Cox and stepwise multiple regression analysis. A predicting model was constructed based on independent factors, and calibrated using Time-dependent ROC curves. Finally, the differentially expressed genes (DEGs) between high-risk and low-risk groups were identified with thresholds $|\log 2(\mathrm{FC})|>0.5$ and $p$ value $<0.05$. And the biofunction was determined by Gene Set Enrichment Analysis (GSEA).

Results

A total 2210 DE-IncTNAs and 2334 DE-mRNAs were identified based on whole transcriptome sequencing. And a total 3724 DEIncRNAs and 2689 DE-mRNAs were identified based on TCGA database. Then, 137 DE-IncRNAs and 278 DE-mRNAs were screened by overlapping RNA sequencing data and TCGA data. A total 13 gene signature were identified to be closely related with OS in BC. Moreover, these 13-OS-related gene signature were identified as independent risk factors with clinical risk factors. Then, a nomogram was constructed and confirmed as the calibration and accuracy predicating model for OS in BC. Finally, a total 739 DEGs were identified between high-risk and low-risk groups, most of DEGs enriched in immune-related pathways. And an OS-related ceRNA network was selected based on 13-OS-related signature.

Conclusion

Our finding provided novel OS-related prognostic signature and reliable predicting model for BC patients, which might facilitate individualized treatment and prognostic evaluation.

\section{Introduction}

Bladder cancer (BC) is a malignant urinary system neoplasm, which causes 549,000 new cases and 200,000 deaths in 2018, and among in men than women about 4 times $[1,2]$. Exposure to chemical, drinking water pollution, and smoking contribute to BC initiation and developing [3], it has been estimated that approximate $50 \%$ of BC cases attribute to smoking in the United States $[4,5]$. In China, BC emerges prevalent with the rapid industrialization, which increasing exposure to occupational chemical [6]. However, the treatment for BC remains unfavorable nowadays. Due to the high heterogeneous malignancy and limited therapeutic strategy, including surgery, immunotherapy, and chemotherapy, the 5-years survival rates of BC reveal flat [79]. Therefore, it is urgent to explore the efficient diagnostic and therapeutic biomarkers for BC.

$\mathrm{BC}$ reveals the clinically and biologically heterogeneous features, thus, molecular characteristics of cancer reflect the cancer initiation, progression, and clinical prognosis, as well as contribute to explore the biomarkers for diagnosis and therapy [10, 11]. Based on advanced the genetic sequencing technologies and computational analysis cause the explosive increasing large cohorts of tumors as well as genomic researches $[12,13]$. Abundant genomic subtypes, molecular classifications, and patient stratification haven been constructed in BC $[14,15]$. Such as, a novel mutant gene HECW1 has been identified according to 
whole-exome sequencing in muscle-invasive transitional cell carcinoma of BC [16]. Moreover, risk prognostic signature of conventional urothelial carcinoma and high grade T1 urothelial BC are identified based on whole transcriptome sequencing analysis [17]. Therefore, transcriptomics and next-generation sequencing (NGS) are powerful for deciphering genome structure and function, exploring genetic network and cell-to-cell interaction [18].

MRNA processing is essential for gene expression to regulate tumorigenesis and development, but also non-coding RNAs (ncRNAs), including circular RNAs (circRNAs), long non-coding RNAs (IncRNAs), and microRNAs (miRNAs) contribute to tumor initiation, progression, and clinical prognosis [19]. IncRNAs is a group of ncRNAs in length more than 200 nucleotides that associate to various functions. IncRNAs exert biological functions display tissue/ell-specific and distribution of subcellular [20]. The biological contributions of IncRNAs include regulating transcription in cis and trans manners, regulating mRNA expression, and organizing nuclear domains [21]. In general, IncRNAs compete with miRNAs to up-regulate mRNA expression by acting as competitive endogenous RNAs (cerRNAs) [22]. Increasing evidences have indicated that IncRNAs play the vital roles in BC progression. Such as IncRNA SOX2OT enhances BC developing and progressing via promoting SOX2 expression [23]. And IncRNA DANCR acts as an oncogene by increasing MSI2 expression via competing miR-149 in BC [24]. Of interest, abundant IncRNAs have been identified as the prognostic biomarkers based on the bioinformatics analysis, for example, autophagy-related LINC02178, AC108449.2, Z83843.1, FAM13A-AS1 and USP30-AS1 function as the prognostic signature for bladder urothelial carcinoma patients [25]. Moreover, UCA1 has been demonstrated as a diagnostic biomarker, and HOTAIR and GAS5 act the biomarkers for disease-free survival, recurrence-free survival, and disease-specific survival in BC [26].

AC005014.2, AC010503.4, AL450384.2, LINC00930 and SH3BP5-AS1 have been found upregulation in BC and associate to immune cell infiltration [27]. However, OS-related signature and ceRNA network in predicting the survival and prognosis of BC remain unclear.

Here, we integrated analysis of whole transcriptomic RNA sequencing and the RNA expression files from the Cancer Genome Atlas (TCGA) database to identify the 13-OS-related signature, and construct and validate the risk model and prognostic predicting model for BC. Finally, the prognostic ceRNA network, LINC01322-hsa-miR-125b-2-3p-IGF2 and LINC01322-hsa-miR6507-5p-MLLT11 were identified as key prognostic ceRNA in BC.

\section{Methods}

\section{Patients and clinical specimen collection}

Three paired tumor tissues and matched normal tissues were obtained from BC patients who underwent surgical resection before chemotherapy or radiotherapy. All patients were known the purpose of this study and signed the inform consents. All experiments performances were approved by the Medical Ethics Committee of the Second Affiliated Hospital of Kunming Medical University. The pathology of BC was confirmed by at least three pathologists before surgery. All specimen were collected and stored in liquid nitrogen.

\section{RNA extraction and quality control}

Total RNA was extracted from tumor tissues and matched normal tissues using TRIzol reagent (Takara, Dalian, China) following the manufacturer's instruction. Then, RNA purity, concentration, and integrity were detected using a NanoPhotometer ${ }^{\circledR}$ spectrophotometer (IMPLEN, CA, USA), Qubit ${ }^{\circledR}$ RNA Assay Kit in Qubit ${ }^{\circledR} 2.0$ Flurometer (Life Technologies, CA, USA), and RNA Nano 6000 assay Kit of a Bioanalyzer 2100 system (Agilent, Technologies, CA, USA), respectively.

\section{Library construction}

After that, the library preparation was performed successive using Epicentre Rbio-zero ${ }^{\text {TM }}$ rRNA Removal Kit (Epicentre, USA) and NEBNext ${ }^{\circledR}$ Ultra ${ }^{\text {TM }}$ Directional RNA Library Prep Kit for Illumina ${ }^{\circledR}$ (NEB, USA) according to the manufacturer's protocol.

Briefly, amount of $3 \mu \mathrm{g}$ RNA per sample was used to the preparation. Firstly, the rRNA was removed using Epicentre Rbio-zero ${ }^{\mathrm{TM}}$ rRNA Removal Kit (Epicentre, USA) and then cleaned up using ethanol precipitation. Secondary, the sequencing libraries were 
generated using NEBNext ${ }^{\circledR}$ Ultra ${ }^{T M}$ Directional RNA Library Prep Kit for Illumina ${ }^{\circledR}$ (NEB, USA) according to the manufacturer's protocol. The procedures of sequencing libraries construction shown as following, the first strand cDNA was synthesized using random hexamer primer and M-MuL V Reverse Transcriptase (RNase $\left.\mathrm{H}^{-}\right)$, the second cDNA then synthesized using DNA Polymerase $\otimes$ and RNase $\mathrm{H}^{-}$. Subsequently, the 3 ' ends of DNA fragments were adenylation via exonuclease and polymerase activities, and NEBNext adaptor with hairpin loop structure were ligated to prepare for hybridization. The cDNA fragments of preferentially 150-200 bp in length were screened with AMPure XP system (Beckman, Coulter, Beverly, USA). After that, the second cDNA fragments which containing uracil (U) were degraded with USER Enzyme (NEB, USA). Then, PCR was performed with Phusion High-Fidelity DNA polymerase, Universal PCR primers and Index (X) Primer. At last, products were purified with AMPure XP system (Beckman, Coulter, Beverly, USA) and library quality was evaluated using Agilent Bioanalyzer 2100 system.

\section{RNA sequencing}

Finally, the cDNA libraries of index-coded samples were clustered using cBot Cluster Generation System using TruSeq PE Cluster Kit v3-cBot-HS (Illumina) following the manufacturer's protocol. Then, the libraries were sequenced on an Illumina Hiseq 4000 platform and 150 bp paired-end reads were generated.

\section{Data analysis}

After RNA-sequencing, raw data of fastq format, which containing adapter, poly- $\mathrm{N}$, and low-quality reads were converted into high-quality clear data. Then, high-quality clear data were mapped to the reference genome using HISAT2 v2.2.1. The reads numbers mapped to each gene were counted using HTSeq v0.13.5. After that, Fragments Per Kilobase of transcript sequence per Millions (FPKM) of each gene was calculated based on the length of the gene and reads count mapped to this gene. Then, the DE-mRNAs and DE-IncRNAs between tumor samples and normal samples were identified using DEGseq2 R package with the thresholds $\mid \log 2$ (Fold change (FC) $\mid>2$ and $p$ value $<0.05$.

\section{Data acquisition and processing}

The expression profiles and clinical information were downloaded from the TCGA-BLCA project of the Genomic Data Commons Data Portal of TCGA (https://portal.gdc.cancer.gov/), which contained $433 \mathrm{BC}$ cases, excluding the non-primary tumors and samples lacking the clinical information, finally, 408 tumor samples and 19 normal samples were used for this study. The RNA expression profiles were normalized using DEGseq2 R package.

\section{Screening of DE-IncRNAs and DE-mRNAs}

DE-mRNAs and DE-IncRNAs were screened using DEGseq2 R package according to the thresholds $|\log 2(\mathrm{FC})|>0.5$ and $p$ value $<0.05$, respectively. Then, differences between tumor and normal were visualized using volcano plots and heatmaps, which performed using ggplot2 $\mathrm{R}$ package and pheatmap $\mathrm{R}$ package, respectively.

\section{Overlapping the RNA-seq data and TCGA data}

To identify the significant DE-mRNAs and DE-IncRNAs in bladder cancer, the DE-mRNAs and DE-IncRNAs were overlapped and identified both in RNA-seq data and TCGA data.

\section{Construction of the IncRNA-miRNA-mRNA network}

The binding relationship between IncRNAs and miRNAs were speculated using miRanda database, and the binding relationship between miRNAs and mRNAs were speculated using Targetscan database. The positive association between IncRNAs and mRNAs was analyzed. Then, the ceRNA network was constructed based on the regulatory speculation, and visualized by Cytoscape software.

\section{Identification of the OS-related DE-IncRNAs and DE-mRNAs in BC patients}


To identify the OS-related DE-IncRNAs and DE-mRNAs, all BC patients were distributed into training set and validation set at a ratio of 7:3. The correlation between DE-IncRNAs/DE-mRNAs and OS were assessed by Kaplan-Meier analysis and Univariate Cox regression analysis. DE-IncRNAs and DE-mRNAs with $p$ value 0.05 and with the consistence between expression and prognostic effects were considered as the candidates OS-related DE-IncRNAs and DE-mRNAs in training set.

\section{Construction and evaluation of the risk model in BC}

After univariate Cox regression analysis, total 35 OS-related candidates (10 DE-IncRNAs and 25 DE-mRNAs) were incorporated into a stepwise multivariate regression model to predicate the prognostic values of 35 OS-related candidates, and 13-OSrelated signature was confirmed as the risk signature. Then, the risk score was calculated based on predict. Coxph fucnion of

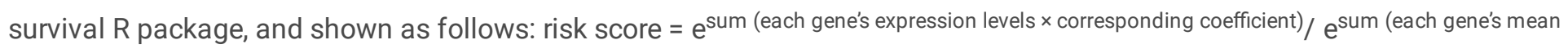
expression levels $\times$ corresponding coefficient). Then, each BC patients in entire sets were assigned a risk score according to the formula. And the patients were divided into high-risk and low-risk groups according to the median risk score. Subsequently, the survival differences between high-risk and low-risk groups were determined by Kaplan-Meier methods and log-rank test. In addition, association between clinical characteristics (such as T/N/M stages, pathological stages, and other clinical risk factors) and independent prognostic signature were determined by a stratified analysis. Moreover, the efficiency of the prognostic model was evaluated by Kaplan-Meier survival curves and time-dependent ROC curves. Furthermore, the association between risk score and clinicopathological characteristics was examined to confirm the reliable and accuracy of risk model.

\section{Construction of the risk signature-based prognostic nomograms}

To identify independent predictors of OS in BC, the clinical factors were incorporated into univariate and stepwise multivariate regression analysis. And a nomogram was constructed to predicate median survival time and 3- and 5-years survival rates of

$\mathrm{BC}$ patients using rms R package. the accuracy of nomograms was calculated by concordance index (C-index) and calibration curves.

\section{Screening of the DEGs between high-risk and low-risk groups in BC patients}

To explore the potential function and mechanism between high-risk and low-risk score groups, the DE-mRNA between high-risk and low-risk score groups were screened out according to the cutoff values $\| \log 2(\mathrm{FC}) \mid>0.5$ and $p$ value $<0.05$.

\section{GSEA analysis (high/low risk score group)}

For further to identify the regulatory mechanism between high-risk and low-risk score groups, GSEA was performed to explore the biofunction of the risk score-related genes. And the GO term, KEGG pathway, and Reactome term were enriched by GSEA. The cutoff was FDR<0.05 and $|\mathrm{NES}|>1$.

\section{Results}

\section{Identification of the DE-IncRNAs and DE-mRNAs and construction of a ceRNA network in BC}

The workflow diagram was constructed to illustrate the designs of this study (Fig. 1). Next-generation sequencing was performed to investigate the differences between tumor tissues and adjacent normal tissues. A total 2210 DE-IncRNAs and $2334 \mathrm{DE}-\mathrm{mRNAs}$ between tumor tissues and normal tissues were screened out according to the criteria |log2 (FC)|>2 and $p$ value 0.05 (Fig. 2A-B, Table S1-2). DE-IncRNAs included 1255 upregulated DE-IncRNAs and 955 downregulated DE-IncRNAs. DE-mRNAs consisted of 689 upregulated DE-mRNAs and 1645 downregulated DE-mRNAs. Moreover, hierarchical clustering displayed that significant difference between tumor samples and normal samples (Fig. 2C-D). Furthermore, the DE-IncRNAs and DE-mRNAs between 408 bladder cancer samples and 19 normal samples were identified. Results indicated that 3,724 DEIncRNAs (2675 upregulated and 1067 downregulated DE-IncRNAs) and 2,689 DE-mRNAs (1261 upregulated DE-mRNAs and 1428 downregulated DE-mRNAs) were identified with threshold $\mid \log 2$ (FC) $\mid>0.5$ and $p$ value< 0.05 (Table S3-4). Then, 137 overlapped DE-IncRNAs and 278 overlapped DE-mRNAs were obtained from RNA-seq data and TCGA data (Fig. 2E-F, Table S5- 
6), which contained 96 upregulated DE-IncRNAs and 41 downregulated DE-IncRNAs, and 47 upregulated DE-mRNAs and 231 downregulated DE-mRNAs. Based on the speculated miRNAs, which directly targeted IncRNAs and mRNAs, the ceRNA network was constructed and visualized in Fig. 2G. The ceRNA network constituted with 17 IncRNAs, 32 mRNAs, and 29 miRNAs, and formed 312 edges and 78 nodes (Table S7).

\section{Screening of 13-OS-related signature from BC based TCGA database}

In order to determine whether these DE-IncRNAs and DE-mRNAs related to the OS in BC patients, these RNAs were filtered with $\mathrm{KM}$ methods and log-rank test. The results suggested that there are 18 DE-IncRNAs and $44 \mathrm{DE}-\mathrm{mRNAs}$ were assessed as OSrelated candidates (Fig. 3, Table 1). Then, univariate Cox analysis was performed to determine whether 18 DE-IncRNAs and 44 DE-mRNAs are the risk factors according to threshold $P<0.05$ (Table 2). Therefore, a total 10 DE-IncRNAs and 25 DE-mRNAs were identified as the risk factors (Fig. 4A, Table 3). Furthermore, the 35 OS-related candidates were incorporated into a stepwise multiple regression model, 13-OS-related candidates, which including 6 DE-IncRNAs and 7 DE-mRNAs were identified

(Fig. 4B, Table 4). The stepwise multiple regression model was confirmed as the finally predicated model, and the 13-OS-related candidates which selected from the stepwise multiple regression model were integrated into predicative signature to calculate the risk score. Based on the median of risk score, entire BC patients were divided into high-risk and low-risk groups, the OS statues and expression files of each patient indicated that high-risk group with low survival rate than low-risk group (Fig. 4C-D). Moreover, the discrimination ability and predictive sensitivity of the predicated model were determined by Kaplan-Meier and time-dependent ROC curves. Kaplan-Meier curve revealed that high-risk group showed shorter survival time compared with lowrisk group (Fig. 4E). Kaplan-Meier curve displayed the AUC value of 1-years, 2-years, 3-years, 4-years, and 5-years OS predication of the prognostic predicted model were $0.695,0.784,0.771,0.760$, and 0.754 in training set, and showed the AUC value of 1-years, 2-years, 3-years, 4-years, and 5-years OS predication of the prognostic predicted model were $0.619,0.641$, $0.657,0.699$, and 0.715 (Fig. 4F-G). Then, we investigated the expression of thirteen OS-related signature in training and validation sets. As shown in Fig. 4H, 13-OS-related signature were separated into two risk subgroups, IGF2, MLT11, KIAA1462, GPIHBP1, PTGIS, LHFP, and EGFR_AS1 upregulated in high-risk group whereas RASL12, RP4_761J14.8, RP3_412A9.17, RP11_92F20.1, RP11_338L22.2, and XXbac_BPG299F13.17 downregulated in low-risk group, in both sets. These data suggested that discrimination ability and predictive sensitivity of the prognostic predictive model based on 13-OS-related signature.

\section{Association between risk score and clinical characteristics}

We further investigated the correlation between risk score and clinical characteristics using Wilcox test or Kruskal-Wallis test. We found that the increasing risk scores positively associated with distant metastasis (M), advanced pathological stages ( $\nabla / \mathbb{\nabla})$, malignant primary tumor $(\mathrm{T})$ (Fig. 5A). In addition, high-risk group showed shorter survival time in patients and not correlated with age and gender stratification (Fig. 5B-C). Besides, the high-risk patients exhibited shorter survival time with or without

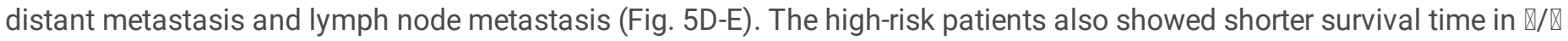
stages (Fig. 5F). Moreover, high-risk patients exhibited poor survival with or without prior malignancy, treatment, and different treatment types (Fig. $5 \mathrm{H}-\mathrm{J}$ ).

\section{Identification and validation of OS-related signature as independent prognostic factors for BC patients}

To identify of the independent risk factors for BC patients, Univariate Cox and stepwise multivariate regression analyses were performed with clinicopathological factors, such as age, gender, T/N/M stages, pathological stages, prior malignancy, treatment, $\mathrm{BMI}$ in entire sets. The results indicated that risk score $(P<0.001)$ was independent prognostic indicator in $\mathrm{BC}($ Fig. 6A-B, Table 5).

\section{Construction and validation of a nomogram for prognostic prediction in BC}

We integrated traditional risk factors, such as age, gender, T/N/M stages, pathological stages, prior malignancy, treatment, BMI, and risk score to construct the prognostic nomograms predicting median survival time, 3-year, and 5-year OS of BC patients using a stepwise multiple regression model (Fig. 7A-B). The concordance index (C-index) and calibration plots were used to 
evaluate the discrimination and calibration abilities of the predictive nomogram. The C-index of predictive nomogram was 0.7312959, and the C-index after calibrating this nomogram was 0.7122346 (Fig. 7C). Then, 3-year and 5-year OS probabilities generated by the nomogram, and results indicated the predicated 3-year and 5-year OS probabilities closed to acute 3-year and 5-year OS probabilities (Fig. 7D-E). Our finding indicated that the effectiveness and sensitivity of the predictive nomogram.

\section{Function analysis of 13 OS-related signature}

GO annotation and KEGG pathway enrichment were performed to analysis the biofunction of 13-OS-related signature. The GO terms including biological processes, cellular components, and molecular processes, in this study, the molecular processes primarily enriched in insulin-like growth factor receptor binding, protein transmembrane transporter activity, protein transporter activity, insulin receptor binding, macromolecule transmembrane transporter activity, protein serine/threonine kinase activator activity, lipoprotein particle binding, peptide transmembrane transporter activity, and intramolecular oxidoreductase activity, IGF2, GPIHBP1, and PTGIS were involved this processes (Fig. S1A). However, there is no significant KEGG pathway enrichment analysis (Fig. S1B). These data suggested that OS-related signature might affect the several biological processes to regulate $\mathrm{BC}$ progression.

\section{Identification of the DEGs between high-risk score group and low-risk score group in BC}

We also examined whether significant differences and potential regulatory mechanism between high-risk score group and lowrisk score group according to the TCGA dataset. As shown in Fig. 8 and Table S8, total 739 DEGs were identified between highrisk score and low-risk score groups, which including 481 upregulated and 258 downregulated DEGs with threshold |log $2(\mathrm{FC}) \mid>0.5$ and $p$ value $<0.05$. The hierarchical clustering revealed that significant differences between high-risk score and lowrisk score groups (Fig. 8B). There are abundant numbers of DEGs between high-risk score and low-risk score groups. In addition, we also found IGF2, PTGIS, LHFPL6, RASL12, MLLT11, JCAD, GPIHBP1, and EGFR-AS1 upregulated in high-risk group compared to low-risk group, but RP4_761J14.8, RP3_412A9.17, RP11_92F20.1, RP11_33BL22.2, and XXbac_BPG299F13.17 downregulated in high-risk group compared to low-risk group (Table S9).

\section{Function analysis of the risk score-related DEGs in BC}

The underlying mechanism of risk score-based DEGs was explored by GSEA. Results revealed that high-risk group mostly associated to biological processes, such as mitotic cell cycle, mRNA metabolic process, DNA metabolic process, etc. (Fig. 9A, 9F, Table 6, Table S10). The related cell components included mitochondrial part, chromosome, chromosome part, nuclear body and so on (Fig. 9B, 9G, Table 6, Table S10). And the molecular functions included double-stranded DNA binding, chromatin binding, ubiquitin-like protein transferase activity and so on (Fig. 9C, 9H, Table 6, Table S10). Besides, KEGG pathway enrichment analysis indicated risk score-based DEGs associated to Herpes simplex virus 1 infection, RNA transport, Spliceosome, mRNA surveillance pathway, etc. (Fig. 9D, 9I, Table 7, Table S11). And the Reactome pathways enrichment revealed risk score-based DEGs mostly enriched in Metabolism of RNA, Cell Cycle, Transcriptional Regulation by TP53, etc. (Fig. 9E, 9J, Table 8, Table S12). Of interest, as shown in Table 9, risk score-based DEGs involved in multiple immune-related pathways. Above results indicated that high risk score patients associated to multiple biological function alterations, including immune dysregulation.

\section{Prognostic ceRNA network analysis}

Based on previous studies, we identified 13 prognostic signature and constructed the ceRNA networks. Therefore, the prognostic ceRNA network, LINC01322-hsa-miR-125b-2-3p-IGF2 and LINC01322-hsa-miR-6507-5p-MLLT11 were selected from the ceRNA network.

\section{Discussion}

$\mathrm{BC}$ remains a tough malignant tumor with the high incidence and mortality, which challenges accurate diagnosis and efficient treatment. More than $90 \%$ patients have been diagnosed as transitional cell carcinoma (TCC), which divides into muscle 
invasive and non-muscle invasive, the muscle invasive BC patients exhibit poorer prognosis and survival rate than others [28]. In the past decades, endoscopic evaluation, biopsies, and intravesical treatment have been used to diagnose and extent periods of survival time, moreover, the high risk patients are treated with chemotherapy, radical cystectomy, and immunotherapy $[29,30]$. However, the prognosis and survival rate for BC patients remain unfavorable. Therefore, based on the whole transcriptomic sequencing and bioinformatic analysis, we found 13-0S-related signature associated to BC, which including 7 mRNAs and 6 IncRNAs. Besides, we also constructed a prognostic model and a predicating model for BC patients, and selected a significant OS-related ceRNA network.

Emerging evidences indicate that IncRNAs exert vital roles in BC initiation and progression, and act as powerful biomarkers for diagnosis and treatment. It has been reported that IncRNA CASC11 plays as an oncogene to accelerate BC cell growth by sponging miR-150 [31]. LncRNA CCAT1 remains promoting BC proliferation, migration, and invasion via inhibiting several miRNAs [32]. Moreover, IncRNA RMRP may be a potentially therapeutic target for BC patients [33]. In addition, abundant numbers of IncRNAs have been identified as the prognostic predictors in BC. Such as, upregulation of IncRNA LINC00641 associates to poor prognosis and promote progression via regulating $\mathrm{h}$ miR-197-3p/KLF10/PTEN/PI3K/AKT cascade in BC [34]. IncRNA GCLNC1 increasing relates to poor survival rates in patients with BC via enhancing MYC expression [35]. Here, we identified that EGFR-AS1 acted as a high-risk factor for BC patients, whereas RP4_761J14.8, RP3_412A9.17, RP11_92F20.1, RP11_338L22.2, and XXbac_BPG299F13.17 were identified as the low-risk factors for BC patients. EGFR-AS1 has been reported that acts as an oncogene in multiple cancers, such as prostate cancer, esophageal squamous cell carcinoma, glioma, renal cancer, non-small lung cancer, and BC [36-41]. Our finding confirmed that EGFR-AS1 promotes BC progression.

Nevertheless, 5 novel IncRNAs, P4_761J14.8, RP3_412A9.17, RP11_92F20.1, RP11_338L22.2, and XXbac_BPG299F13.17 have been found that associated to favorable prognosis of $B C$ patients.

Additionally, IGF2, MLLT11, RASL12, KIAA1462, GPIHBP1, PTGIS, and LHFP were identified as the risk factors for BC. RASL12 and KIAA1462 associated to optimistic prognosis whereas IGF2, MLLT11, GPIHBP1, PTGIS, and LHPF related to poor prognosis of BC patients. RASL12 is one number of RAS-related guanosine triphosphatases (GTPases), which function as the tumor suppresser [42]. However, the tumor suppressor function of RASL12 rarely has been reported. KIAA1462, also named as Junctional cadherin 5 associated (JCAD5), is a coronary artery disease associated gene [43]. It has been reported acting as an oncogene in liver cancer, but its role and regulatory mechanism in BC remain unknown. Our finding predicated that KIAA1462 might act as a tumor suppressor in BC. IGF2 is a mitogenic peptide hormone and expressed in liver and many other tissues, it also associates to metabolic processes [44]. Previous studies have indicated that IGF2 expression promotes BC aggressive behaviors and serves as a prognostic biomarker for BC $[45,46]$. In the present study, IGF2 also has been demonstrated as a prognostic biomarker for BC. MLLT11, known as ALL1-fused gene from the chromosome 1q (AF1q), has been found as an oncogene in multiple cancers and is related to poor outcome of cancers [47-51]. Despite MLLT11 has been found relating to BC development, the prognostic predicting value remains unclear. Here, our results revealed MLLT11 served as a prognostic biomarker for BC. GPIHBP1, also named as glycosylphosphatidylinositol-anchored high-density lipoprotein-binding protein, which is a GPI-anchored protein of capillary endothelial cells and necessary for lipoprotein lipase (LPL)-mediated triglyceriderich lipoproteins (TRLs) processing $[52,53]$. It has been found upregulation in gliomas and breast cancer $[53,54]$. There are firstly found in BC. PTGIS, a prostacyclin synthase, have the function of dilating blood vessels and inhibiting platelet aggregation [55]. High expression of PTGIS associates liver metastasis and poor prognosis in colon cancer patients [56]. It also has bene found PTGIS associates to immune cell infiltration in lung cancer, ovarian cancer, and gastric cancer [57]. However, the regulatory mechanism of PTGIS in BC remains unclear. LHFP, is a member of LHFP family, upregulation of LHFP associates with mesenchymal differentiation in gliosarcoma $[58,59]$. It almost has no reported in other cancers. Although LHFP has been identified as a prognostic biomarker in $\mathrm{BC}$, the role and mechanism of it also need furtherly investigate.

Furthermore, we also demonstrated that T/N/M stages, pathologic stage, and 13-OS-related signature were identified as the independent risk factors in BC. And we also constructed a reliable predicting model for BC patients. Traditionally, T/N/M stages and pathologic stage are the criterion for establishing the treatment and assessing the prognosis for cancer patients [60]. Moreover, it also exhibits various responses for similar treatment in different stages of patients [61]. Therefore, in our study, the clinical factors combine with molecular profiling are need for constructing the reliable predicting model. Hence, the prognostic 
model and predicating model in this study are reliable in BC. The BC samples from TCGA database were divided into high-risk

and low-risk groups, the DEGs and regulatory mechanism between high-risk and low-risk groups were explored. We found most of DEGs enriched in mRNA processing, DNA replication, and metabolic processing. Of interest, numerous immune-related pathways have been enriched in high-risk and low-risk groups. Finally, based on the OS-related signature, an OS-related ceRNA network in $\mathrm{BC}$ has been selected.

\section{Conclusion}

Taken together, we identified 13-OS-related signature, which acted as prognostic biomarkers for BC. Based on 13-OS-related signature we constructed a reliable predicting model to predict the survival time in BC. In addition, we also identified DEGs and pathways in high-risk and low-risk groups based on 13-OS-related signature, and selected an OS-related ceRNA network in BC. Our finding supplied 13 prognostic factors and predicting model in BC. Therefore, we further to explore the function and potential mechanism of these genes in the subsequent studies.

\section{Abbreviations}

BC: Bladder cancer; IncRNA: Long non-coding RNA; ceRNA:Competing endogenous RNA; miRNA: MicroRNA; DEGs: Differentially expressed genes; DE-IncRNAs: Differentially expressed IncRNAs; DE-mRNAs: Differentially expressed mRNAs; TCGA: The cancer genome atlas; OS: Overall survival; GSEA: Gene set enrichment analysis; FPKM: Fragments Per Kilobase of transcript sequence per Millions; FC: Fold change

\section{Declarations}

\section{Acknowledgements}

Not applicable

\section{Authors' contributions}

Conceptualization ideas: Shi-wei Xiao, Jian-song Wang.

Formal analysis: Shi-wei Xiao®Ying-long Huang.

Investigation: Shi-wei Xiao, Ya-nan Li, Dong-bo Yuan.

Methodology: Shi-wei Xiao, Yi-gang Zuo, Ying-long Huang.

Project administration: Shi-wei Xiao, Hai-feng Wang, Jian-song Wang.

Resources: Hai-feng Wang, Jian-song Wang.

Supervision: Jian-song Wang. Hai-feng Wang.

Verification: Shi-wei Xiao, Ya-nan Li.

Writing - original draft: Shi-wei Xiao.

Writing - review \& editing: Jian-song Wang, Hai-feng Wang.

All authors read and approved this final manuscript.

\section{Availability of data and materials}

The datasets analyzed during the current study are available in theTCGA database (https://portal.gdc.cancer.gov/). 


\section{Ethics approval and consent to participate}

All patients were known the purpose of this study and signed the inform consents. All experiments performances were approved by the Medical Ethics Committee of the Second Affiliated Hospital of Kunming Medical University.

\section{Consent for publication}

All authors agree to publish.

\section{Competing interests}

The authors declare that they have no competing interests.

\section{Funding}

This work was supported by the National Natural Science Foundation of China (No. 82060464, No. 81860452), Science and Technology Foundation of Guizhou Provincial Health Commission (No.gzwjkj2019-1-130), Science and Technology Innovation Team of Basic and Clinical Research of Bladder Cancer in Yunnan Universities (K1322107).

\section{Author details}

${ }^{1}$ Department of Urology, The Second Affiliated Hospital of Kunming Medical University, Yunnan Institute of Urology, Kunming, China;

${ }^{2}$ Department of Urology, Guizhou Provincial People's Hospital, Guiyang, China;

${ }^{3}$ Shool of Pharmacy, Guizhou University of Traditional Chinese Medicine, Guiyang, China.

\section{References}

1. Bray F, Ferlay J, Soerjomataram I, Siegel RL, Torre LA, Jemal A. Global cancer statistics 2018: GLOBOCAN estimates of incidence and mortality worldwide for 36 cancers in 185 countries. CA Cancer J Clin. 2018;68(6): 394-424.

2. Dobruch J, Daneshmand S, Fisch M, Lotan Y, Noon AP, Resnick MJ, et al. Gender and Bladder Cancer: A Collaborative Review of Etiology, Biology, and Outcomes. Eur Urol. 2016;69(2): 300-310.

3. Antoni S, Ferlay J, Soerjomataram I, Znaor A, Jemal A, Bray F. Bladder Cancer Incidence and Mortality: A Global Overview and Recent Trends. Eur Urol. 2017;71(1): 96-108.

4. Freedman ND, Silverman DT, Hollenbeck AR, Schatzkin A, Abnet CC. Association between smoking and risk of bladder cancer among men and women. Jama. 2011;306(7): 737-745.

5. Islami F, Goding Sauer A, Miller KD, Siegel RL, Fedewa SA, Jacobs EJ, et al. Proportion and number of cancer cases and deaths attributable to potentially modifiable risk factors in the United States. CA Cancer J Clin. 2018;68(1): 31-54.

6. Liu X, Jiang J, Yu C, Wang Y, Sun Y, Tang J, et al. Secular trends in incidence and mortality of bladder cancer in China, 19902017: A joinpoint and age-period-cohort analysis. Cancer Epidemiol. 2019;61(95-103.

7. Grayson M. Bladder cancer. Nature. 2017;551(7679): S33.

8. Siracusano S, Rizzetto R, Porcaro AB. Bladder cancer genomics. Urologia. 2020;87(2): 49-56.

9. Ma G, Yang X, Liang Y, Wang L, Li D, Chen Y, et al. Precision medicine and bladder cancer heterogeneity. Bull Cancer. 2018;105(10): 925-931. 
10. Jalanko T, de Jong JJ, Gibb EA, Seiler R, Black PC. Genomic Subtyping in Bladder Cancer. Curr Urol Rep. 2020;21(2): 9.

11. Sjödahl G, Jackson CL, Bartlett JM, Siemens DR, Berman DM. Molecular profiling in muscle-invasive bladder cancer: more than the sum of its parts. J Pathol. 2019;247(5): 563-573.

12. Pareek CS, Smoczynski R, Tretyn A. Sequencing technologies and genome sequencing. J Appl Genet. 2011;52(4): 413-435.

13. Kumar KR, Cowley MJ, Davis RL. Next-Generation Sequencing and Emerging Technologies. Semin Thromb Hemost. 2019;45(7): 661-673.

14. Kamoun A, de Reyniès A, Allory Y, Sjödahl G, Robertson AG, Seiler R, et al. A Consensus Molecular Classification of Muscleinvasive Bladder Cancer. Eur Urol. 2020;77(4): 420-433.

15. Alifrangis C, McGovern U, Freeman A, Powles T, Linch M. Molecular and histopathology directed therapy for advanced bladder cancer. Nat Rev Urol. 2019;16(8): 465-483.

16. Pan H, Xu X, Wu D, Qiu Q, Zhou S, He X, et al. Novel somatic mutations identified by whole-exome sequencing in muscleinvasive transitional cell carcinoma of the bladder. Oncol Lett. 2016;11(2): 1486-1492.

17. Bowden M, Nadal R, Zhou CW, Werner L, Barletta J, Juanpere N, et al. Transcriptomic analysis of micropapillary high grade T1 urothelial bladder cancer. Sci Rep. 2020;10(1): 20135.

18. Jiang Z, Zhou X, Li R, Michal JJ, Zhang S, Dodson MV, et al. Whole transcriptome analysis with sequencing: methods, challenges and potential solutions. Cell Mol Life Sci. 2015;72(18): 3425-3439.

19. Goodall GJ, Wickramasinghe VO. RNA in cancer. Nat Rev Cancer. 2021;21(1): 22-36.

20. de Hoon M, Shin JW, Carninci P. Paradigm shifts in genomics through the FANTOM projects. Mamm Genome. 2015;26(910): 391-402.

21. Sanchez Calle A, Kawamura Y, Yamamoto Y, Takeshita F, Ochiya T. Emerging roles of long non-coding RNA in cancer. Cancer Sci. 2018;109(7): 2093-2100.

22. Zhang G, Li S, Lu J, Ge Y, Wang Q, Ma G, et al. LncRNA MT1JP functions as a ceRNA in regulating FBXW7 through competitively binding to miR-92a-3p in gastric cancer. Mol Cancer. 2018;17(1): 87.

23. Zhan Y, Chen Z, He S, Gong Y, He A, Li Y, et al. Long non-coding RNA SOX2OT promotes the stemness phenotype of bladder cancer cells by modulating SOX2. Mol Cancer. 2020;19(1): 25.

24. Zhan Y, Chen Z, Li Y, He A, He S, Gong Y, et al. Long non-coding RNA DANCR promotes malignant phenotypes of bladder cancer cells by modulating the miR-149/MSI2 axis as a ceRNA. J Exp Clin Cancer Res. 2018;37(1): 273.

25. Sun Z, Jing C, Xiao C, Li T. An autophagy-related long non-coding RNA prognostic signature accurately predicts survival outcomes in bladder urothelial carcinoma patients. Aging (Albany NY). 2020;12(15): 15624-15637.

26. Quan J, Pan X, Zhao L, Li Z, Dai K, Yan F, et al. LncRNA as a diagnostic and prognostic biomarker in bladder cancer: a systematic review and meta-analysis. Onco Targets Ther. 2018;11(6415-6424.

27. Cao R, Yuan L, Ma B, Wang G, Tian Y. Immune-related long non-coding RNA signature identified prognosis and immunotherapeutic efficiency in bladder cancer (BLCA). Cancer Cell Int. 2020;20(276.

28. Li HT, Duymich CE, Weisenberger DJ, Liang G. Genetic and Epigenetic Alterations in Bladder Cancer. Int Neurourol J. 2016;20(Suppl 2): S84-94. 
29. Bhanvadia SK. Bladder Cancer Survivorship. Curr Urol Rep. 2018;19(12): 111.

30. Vasekar M, Degraff D, Joshi M. Immunotherapy in Bladder Cancer. Curr Mol Pharmacol. 2016;9(3): 242-251.

31. Luo H, Xu C, Le W, Ge B, Wang T. IncRNA CASC11 promotes cancer cell proliferation in bladder cancer through miRNA-150. J Cell Biochem. 2019;120(8): 13487-13493.

32. Zhang C, Wang W, Lin J, Xiao J, Tian Y. IncRNA CCAT1 promotes bladder cancer cell proliferation, migration and invasion. Int Braz J Urol. 2019;45(3): 549-559.

33. Cao HL, Liu ZJ, Huang PL, Yue YL, Xi JN. IncRNA-RMRP promotes proliferation, migration and invasion of bladder cancer via miR-206. Eur Rev Med Pharmacol Sci. 2019;23(3): 1012-1021.

34. Li Z, Hong S, Liu Z. LncRNA LINC00641 predicts prognosis and inhibits bladder cancer progression through miR-1973p/KLF10/PTEN/PI3K/AKT cascade. Biochem Biophys Res Commun. 2018;503(3): 1825-1829.

35. Zhuang C, Ma Q, Zhuang C, Ye J, Zhang F, Gui Y. LncRNA GCInc1 promotes proliferation and invasion of bladder cancer through activation of MYC. Faseb j. 2019;33(10): 11045-11059.

36. Dong ZQ, Guo ZY, Xie J. The IncRNA EGFR-AS1 is linked to migration, invasion and apoptosis in glioma cells by targeting miR-133b/RACK1. Biomed Pharmacother. 2019;118(109292.

37. Zeng XY, Jiang XY, Yong JH, Xie H, Yuan J, Zeng D, et al. IncRNA ABHD11-AS1, regulated by the EGFR pathway, contributes to the ovarian cancer tumorigenesis by epigenetically suppressing TIMP2. Cancer Med. 2019;8(16): 7074-7085.

38. Feng Z, Li X, Qiu M, Luo R, Lin J, Liu B. LncRNA EGFR-AS1 Upregulates ROCK1 by Sponging miR-145 to Promote Esophageal Squamous Cell Carcinoma Cell Invasion and Migration. Cancer Biother Radiopharm. 2020;35(1): 66-71.

39. Wang A, Bao Y, Wu Z, Zhao T, Wang D, Shi J, et al. Long noncoding RNA EGFR-AS1 promotes cell growth and metastasis via affecting HuR mediated mRNA stability of EGFR in renal cancer. Cell Death Dis. 2019;10(3): 154.

40. Xu YH, Tu JR, Zhao TT, Xie SG, Tang SB. Overexpression of IncRNA EGFR-AS1 is associated with a poor prognosis and promotes chemotherapy resistance in non-small cell lung cancer. Int J Oncol. 2019;54(1): 295-305.

41. Wang A, Jiang A, Gan X, Wang Z, Huang J, Dong K, et al. EGFR-AS1 Promotes Bladder Cancer Progression by Upregulating EGFR. Biomed Res Int. 2020;2020(6665974.

42. Dhanaraman T, Singh S, Killoran RC, Singh A, Xu X, Shifman JM, et al. RASSF effectors couple diverse RAS subfamily GTPases to the Hippo pathway. Sci Signal. 2020;13(653).

43. Xu S, Xu Y, Liu P, Zhang S, Liu H, Slavin S, et al. The novel coronary artery disease risk gene JCAD/KIAA1462 promotes endothelial dysfunction and atherosclerosis. Eur Heart J. 2019;40(29): 2398-2408.

44. Livingstone C. IGF2 and cancer. Endocr Relat Cancer. 2013;20(6): R321-339.

45. Chiu YF, Wu CC, Kuo MH, Miao CC, Zheng MY, Chen PY, et al. Critical role of SOX2-IGF2 signaling in aggressiveness of bladder cancer. Sci Rep. 2020;10(1): 8261.

46. Amit D, Tamir S, Birman T, Gofrit ON, Hochberg A. Development of targeted therapy for bladder cancer mediated by a double promoter plasmid expressing diphtheria toxin under the control of IGF2-P3 and IGF2-P4 regulatory sequences. Int J Clin Exp Med. 2011;4(2): 91-102.

47. Co NN, Tsang WP, Tsang TY, Yeung CL, Yau PL, Kong SK, et al. AF1q enhancement of gamma irradiation-induced apoptosis by up-regulation of BAD expression via NF-kappaB in human squamous carcinoma A431 cells. Oncol Rep. 2010;24(2): 547-

Page $12 / 32$ 
554.

48. Jin H, Sun W, Zhang Y, Yan H, Liufu H, Wang S, et al. MicroRNA-411 Downregulation Enhances Tumor Growth by Upregulating MLLT11 Expression in Human Bladder Cancer. Mol Ther Nucleic Acids. 2018;11(312-322.

49. Zhang HP, Chen QK, Xu JF. LPAR5 stimulates the malignant progression of non-small-cell lung carcinoma by upregulating MLLT11. Eur Rev Med Pharmacol Sci. 2020;24(17): 8902-8910.

50. Tse W, Meshinchi S, Alonzo TA, Stirewalt DL, Gerbing RB, Woods WG, et al. Elevated expression of the AF1q gene, an MLL fusion partner, is an independent adverse prognostic factor in pediatric acute myeloid leukemia. Blood. 2004;104(10): 30583063.

51. Tiberio P, Lozneanu L, Angeloni V, Cavadini E, Pinciroli P, Callari M, et al. Involvement of AF1q/MLLT11 in the progression of ovarian cancer. Oncotarget. 2017;8(14): 23246-23264.

52. Pei-Ling Chiu A, Wang F, Lal N, Wang Y, Zhang D, Hussein B, et al. Endothelial cells respond to hyperglycemia by increasing the LPL transporter GPIHBP1. Am J Physiol Endocrinol Metab. 2014;306(11): E1274-1283.

53. Hu X, Matsumoto K, Jung RS, Weston TA, Heizer PJ, He C, et al. GPIHBP1 expression in gliomas promotes utilization of lipoprotein-derived nutrients. Elife. 2019;8(

54. Bao Y, Wang L, Shi L, Yun F, Liu X, Chen Y, et al. Transcriptome profiling revealed multiple genes and ECM-receptor interaction pathways that may be associated with breast cancer. Cell Mol Biol Lett. 2019;24(38.

55. Ershov PV, Mezentsev YV, Kopylov AT, Yablokov EO, Svirid AV, Lushchyk AY, et al. Affinity Isolation and Mass Spectrometry Identification of Prostacyclin Synthase (PTGIS) Subinteractome. Biology (Basel). 2019;8(2).

56. Lichao S, Liang P, Chunguang G, Fang L, Zhihua Y, Yuliang R. Overexpression of PTGIS could predict liver metastasis and is correlated with poor prognosis in colon cancer patients. Pathol Oncol Res. 2012;18(3): 563-569.

57. Dai D, Chen B, Feng Y, Wang W, Jiang $Y$, Huang $H$, et al. Prognostic value of prostaglandin $I 2$ synthase and its correlation with tumor-infiltrating immune cells in lung cancer, ovarian cancer, and gastric cancer. Aging (Albany NY). 2020;12(10): 96589685.

58. Petit MM, Schoenmakers EF, Huysmans C, Geurts JM, MandahI N, Van de Ven WJ. LHFP, a novel translocation partner gene of HMGIC in a lipoma, is a member of a new family of LHFP-like genes. Genomics. 1999;57(3): 438-441.

59. Nagaishi M, Kim YH, Mittelbronn M, Giangaspero F, Paulus W, Brokinkel B, et al. Amplification of the STOML3, FREM2, and LHFP genes is associated with mesenchymal differentiation in gliosarcoma. Am J Pathol. 2012;180(5): 1816-1823.

60. Ramos M, Franch P, Zaforteza M, Artero J, Durán M. Completeness of T, N, M and stage grouping for all cancers in the Mallorca Cancer Registry. BMC Cancer. 2015;15(847.

61. Chen Q, Fu YY, Yue QN, Wu Q, Tang Y, Wang WY, et al. Distribution of PD-L1 expression and its relationship with clinicopathological variables: an audit from 1071 cases of surgically resected non-small cell lung cancer. Int J Clin Exp Pathol. 2019;12(3): 774-786.

\section{Tables}

Table 162 significant survival-related DE-mRNAs and DE-IncRNAs in BC. 


\begin{tabular}{|c|c|}
\hline gene or Clinical features & $P$ value \\
\hline C14orf132 & 0.0028 \\
\hline C8orf88 & 0.0161 \\
\hline CALD1 & 0.0096 \\
\hline CCDC80 & 0.0165 \\
\hline CD248 & 0.001 \\
\hline CHRDL1 & 0.0311 \\
\hline CLIP3 & 0.0449 \\
\hline COL14A1 & 0.01 \\
\hline COL21A1 & 0.0406 \\
\hline COL6A2 & 0.0203 \\
\hline CTSG & 0.0162 \\
\hline CYR61 & 0.0114 \\
\hline EFEMP1 & 0.0098 \\
\hline EGR2 & 0.0385 \\
\hline FLNC & 0.0301 \\
\hline GEM & 0.0435 \\
\hline GPIHBP1 & 0.0281 \\
\hline IGDCC4 & 0.0056 \\
\hline IGF2 & 4.00E-04 \\
\hline KCNK3 & 0.0339 \\
\hline KIAA1462 & 0.0458 \\
\hline KLHL23 & 0.0354 \\
\hline LHFP & 0.0039 \\
\hline MFAP4 & 0.0032 \\
\hline MLLT11 & 0.0246 \\
\hline NFE2L3 & 0.0359 \\
\hline P2RY1 & 0.0411 \\
\hline PID1 & 5.00E-04 \\
\hline PTGFR & 0.0141 \\
\hline PTGIS & 0.023 \\
\hline PTRF & 0.0459 \\
\hline RASL12 & 0.0037 \\
\hline SMYD2 & 0.017 \\
\hline SOBP & 0.0248 \\
\hline
\end{tabular}

Page 14/32 


\begin{tabular}{|ll|}
\hline SPON1 & 0.006 \\
\hline SPRN & 0.0206 \\
\hline TGFB1I1 & $5.00 E-04$ \\
\hline TMEM100 & 0.028 \\
\hline TNFAIP8L3 & 0.0343 \\
\hline TPM2 & 0.0278 \\
\hline TPPP3 & 0.0177 \\
\hline UNC5C & 0.0168 \\
\hline ZNF117 & 0.0199 \\
\hline ZNF521 & 0.0032 \\
\hline CTB_186G2.1 & 0.0088 \\
\hline CTB_31020.4 & 0.0287 \\
\hline EGFR_AS1 & 0.036 \\
\hline IL10RB_AS1 & 0.0142 \\
\hline LINC00702 & 0.005 \\
\hline LINC01322 & 0.0143 \\
\hline RP11_338L22.2 & 0.0171 \\
\hline RP11_355N15.3 & 0.0319 \\
\hline RP11_362K14.5 & 0.0442 \\
\hline RP11_417E7.2 & 0.0191 \\
\hline RP11_7F17.8 & 0.0098 \\
\hline RP11_92F20.1 & 0.0059 \\
\hline RP3_412A9.17 & 0.0068 \\
\hline RP3_508I15.18 & 0.0371 \\
\hline RP4_635E18.7 & \\
\hline RP4_761J14.8 & 0.0349 \\
\hline SPAG5_AS1 & \\
\hline XXbac_BPG299F13.17 & 0.0126 \\
\hline
\end{tabular}

Table 2 Univariate Cox analysis of the of 25 DE-mRNAs and 10 DE-IncRNAs in BC. 


\begin{tabular}{|c|c|c|c|c|c|}
\hline Gene symbol & Coefficient & $\mathrm{HR}(95 \% \mathrm{Cl}$ for HR) & Wald. test & $\mathbf{z}$ & $P$. value \\
\hline SMYD2 & 0.33 & $1.4(1.1-1.8)$ & 6.6 & 2.6 & 0.01 \\
\hline SPRN & -0.31 & $0.73(0.54-0.99)$ & 4 & -2 & 0.045 \\
\hline IGF2 & 0.088 & $1.1(1-1.1)$ & 13 & 3.5 & 0.00039 \\
\hline MLLT11 & 0.14 & $1.2(1-1.3)$ & 4.6 & 2.2 & 0.031 \\
\hline CALD1 & 0.14 & $1.1(1-1.3)$ & 5.3 & 2.3 & 0.021 \\
\hline FLNC & 0.093 & $1.1(1-1.2)$ & 4.6 & 2.1 & 0.032 \\
\hline RASL12 & 0.14 & $1.2(1-1.3)$ & 4.9 & 2.2 & 0.027 \\
\hline PID1 & 0.17 & $1.2(1-1.4)$ & 4.2 & 2 & 0.04 \\
\hline CLIP3 & 0.13 & $1.1(1-1.3)$ & 4.4 & 2.1 & 0.037 \\
\hline TGFB1I1 & 0.2 & $1.2(1.1-1.4)$ & 7.3 & 2.7 & 0.0068 \\
\hline COL14A1 & 0.18 & $1.2(1.1-1.3)$ & 8.5 & 2.9 & 0.0036 \\
\hline MFAP4 & 0.11 & $1.1(1-1.2)$ & 6.1 & 2.5 & 0.014 \\
\hline KIAA1462 & 0.16 & $1.2(1-1.3)$ & 4.9 & 2.2 & 0.027 \\
\hline GPIHBP1 & 0.18 & $1.2(1-1.4)$ & 4.2 & 2 & 0.041 \\
\hline PTGIS & 0.1 & $1.1(1-1.2)$ & 6 & 2.5 & 0.014 \\
\hline CCDC80 & 0.13 & $1.1(1-1.3)$ & 6.7 & 2.6 & 0.0096 \\
\hline LHFP & 0.25 & $1.3(1.1-1.5)$ & 9.7 & 3.1 & 0.0018 \\
\hline SPON1 & 0.11 & $1.1(1-1.2)$ & 5.1 & 2.3 & 0.024 \\
\hline UNC5C & 0.29 & $1.3(1.1-1.7)$ & 6.9 & 2.6 & 0.0088 \\
\hline IGDCC4 & 0.24 & $1.3(1-1.6)$ & 5.2 & 2.3 & 0.023 \\
\hline CD248 & 0.16 & $1.2(1-1.3)$ & 6.2 & 2.5 & 0.013 \\
\hline ZNF521 & 0.21 & $1.2(1.1-1.4)$ & 6.8 & 2.6 & 0.0093 \\
\hline COL6A2 & 0.1 & $1.1(1-1.2)$ & 4.6 & 2.1 & 0.032 \\
\hline TPPP3 & 0.14 & $1.2(1-1.3)$ & 5.8 & 2.4 & 0.016 \\
\hline EFEMP1 & 0.099 & $1.1(1-1.2)$ & 6.2 & 2.5 & 0.013 \\
\hline RP4_635E18.7 & -1 & $0.36(0.15-0.89)$ & 4.9 & -2.2 & 0.026 \\
\hline RP4_761J14.8 & -1.1 & $0.33(0.12-0.89)$ & 4.8 & -2.2 & 0.029 \\
\hline RP11_417E7.2 & 0.16 & $1.2(1-1.3)$ & 5.9 & 2.4 & 0.015 \\
\hline RP3_412A9.17 & -13 & $2.6 e-06(2 e-10-0.034)$ & 7.1 & -2.7 & 0.0078 \\
\hline SPAG5_AS1 & -0.5 & $0.6(0.39-0.94)$ & 5 & -2.2 & 0.026 \\
\hline EGFR_AS1 & 0.39 & $1.5(1.1-1.9)$ & 7.7 & 2.8 & 0.0056 \\
\hline RP11_92F20.1 & -1.5 & $0.21(0.066-0.69)$ & 6.6 & -2.6 & 0.01 \\
\hline RP11_338L22.2 & -3.2 & $0.042(0.0046-0.39)$ & 7.8 & -2.8 & 0.0054 \\
\hline XXbac_BPG299F13.17 & -0.52 & $0.6(0.41-0.86)$ & 7.8 & -2.8 & 0.0051 \\
\hline
\end{tabular}




\begin{tabular}{|llllll|} 
RP11_7F17.8 & -0.88 & $0.41(0.22-0.8)$ & 6.9 & -2.6 & 0.0085 \\
\hline
\end{tabular}

Table 335 significant genes both by Univariate Cox analysis and $\mathrm{KM}$ analysis in BC. 


\begin{tabular}{|c|c|c|c|c|c|c|}
\hline Gene symbol & Coefficient & $\mathrm{HR}(95 \% \mathrm{Cl}$ for HR) & Wald. test & $\mathbf{z}$ & Cox Pvalue & $\mathrm{KM} P$ value \\
\hline SMYD2 & 0.33 & $1.4(1.1-1.8)$ & 6.6 & 2.6 & 0.01 & 0.016977168 \\
\hline SPRN & -0.31 & $0.73(0.54-0.99)$ & 4 & -2 & 0.045 & 0.020553935 \\
\hline IGF2 & 0.088 & $1.1(1-1.1)$ & 13 & 3.5 & 0.00039 & 0.000399633 \\
\hline MLLT11 & 0.14 & $1.2(1-1.3)$ & 4.6 & 2.2 & 0.031 & 0.024637757 \\
\hline CALD1 & 0.14 & $1.1(1-1.3)$ & 5.3 & 2.3 & 0.021 & 0.009588017 \\
\hline FLNC & 0.093 & $1.1(1-1.2)$ & 4.6 & 2.1 & 0.032 & 0.03006371 \\
\hline RASL12 & 0.14 & $1.2(1-1.3)$ & 4.9 & 2.2 & 0.027 & 0.003715353 \\
\hline PID1 & 0.17 & $1.2(1-1.4)$ & 4.2 & 2 & 0.04 & 0.000487617 \\
\hline CLIP3 & 0.13 & $1.1(1-1.3)$ & 4.4 & 2.1 & 0.037 & 0.044899614 \\
\hline TGFB1I1 & 0.2 & $1.2(1.1-1.4)$ & 7.3 & 2.7 & 0.0068 & 0.000481368 \\
\hline COL14A1 & 0.18 & $1.2(1.1-1.3)$ & 8.5 & 2.9 & 0.0036 & 0.00997827 \\
\hline MFAP4 & 0.11 & $1.1(1-1.2)$ & 6.1 & 2.5 & 0.014 & 0.003225683 \\
\hline KIAA1462 & 0.16 & $1.2(1-1.3)$ & 4.9 & 2.2 & 0.027 & 0.045800571 \\
\hline GPIHBP1 & 0.18 & $1.2(1-1.4)$ & 4.2 & 2 & 0.041 & 0.028058123 \\
\hline PTGIS & 0.1 & $1.1(1-1.2)$ & 6 & 2.5 & 0.014 & 0.022982575 \\
\hline CCDC80 & 0.13 & $1.1(1-1.3)$ & 6.7 & 2.6 & 0.0096 & 0.016467292 \\
\hline LHFP & 0.25 & $1.3(1.1-1.5)$ & 9.7 & 3.1 & 0.0018 & 0.003923056 \\
\hline SPON1 & 0.11 & $1.1(1-1.2)$ & 5.1 & 2.3 & 0.024 & 0.005957644 \\
\hline UNC5C & 0.29 & $1.3(1.1-1.7)$ & 6.9 & 2.6 & 0.0088 & 0.016820479 \\
\hline IGDCC4 & 0.24 & $1.3(1-1.6)$ & 5.2 & 2.3 & 0.023 & 0.005605966 \\
\hline CD248 & 0.16 & $1.2(1-1.3)$ & 6.2 & 2.5 & 0.013 & 0.000988525 \\
\hline ZNF521 & 0.21 & $1.2(1.1-1.4)$ & 6.8 & 2.6 & 0.0093 & 0.003152521 \\
\hline COL6A2 & 0.1 & $1.1(1-1.2)$ & 4.6 & 2.1 & 0.032 & 0.020323121 \\
\hline TPPP3 & 0.14 & $1.2(1-1.3)$ & 5.8 & 2.4 & 0.016 & 0.017684884 \\
\hline EFEMP1 & 0.099 & $1.1(1-1.2)$ & 6.2 & 2.5 & 0.013 & 0.009837627 \\
\hline RP4_635E18.7 & -1 & $0.36(0.15-0.89)$ & 4.9 & -2.2 & 0.026 & 0.046653654 \\
\hline RP4_761J14.8 & -1.1 & $0.33(0.12-0.89)$ & 4.8 & -2.2 & 0.029 & 0.002109411 \\
\hline RP11_417E7.2 & 0.16 & $1.2(1-1.3)$ & 5.9 & 2.4 & 0.015 & 0.019106815 \\
\hline RP3_412A9.17 & -13 & $2.6 \mathrm{e}-06(2 \mathrm{e}-10-0.034)$ & 7.1 & -2.7 & 0.0078 & 0.006753141 \\
\hline SPAG5_AS1 & -0.5 & $0.6(0.39-0.94)$ & 5 & -2.2 & 0.026 & 0.034855029 \\
\hline EGFR_AS1 & 0.39 & $1.5(1.1-1.9)$ & 7.7 & 2.8 & 0.0056 & 0.036033844 \\
\hline RP11_92F20.1 & -1.5 & $0.21(0.066-0.69)$ & 6.6 & -2.6 & 0.01 & 0.005874754 \\
\hline RP11_338L22.2 & -3.2 & $0.042(0.0046-0.39)$ & 7.8 & -2.8 & 0.0054 & 0.017103922 \\
\hline XXbac_BPG299F13.17 & -0.52 & $0.6(0.41-0.86)$ & 7.8 & -2.8 & 0.0051 & 0.012648268 \\
\hline
\end{tabular}


Table 4 Stepwise multivariable regression analysis of 13-0S-related signature in BC.

\begin{tabular}{|lllll|}
\hline Gene symbol & Coefficient & HR (95\% Cl for HR) & $\mathbf{z}$ & Pvalue \\
\hline IGF2 & 0.072 & $1.1(1-1.1)$ & 2.7 & 0.008 \\
\hline MLLT11 & 0.28 & $1.3(1.1-1.5)$ & 3.6 & 0.00034 \\
\hline RASL12 & -0.25 & $0.78(0.59-1)$ & -1.8 & 0.075 \\
\hline KIAA1462 & -0.2 & $0.82(0.65-1)$ & -1.7 & 0.097 \\
\hline GPIHBP1 & 0.21 & $1.2(0.96-1.6)$ & 1.6 & 0.1 \\
\hline PTGIS & 0.13 & $1.1(0.99-1.3)$ & 1.8 & 0.064 \\
\hline LHFP & 0.31 & $1.4(1-1.8)$ & 2.1 & 0.037 \\
\hline RP4_761J14.8 & -1.5 & $0.22(0.069-0.67)$ & -2.6 & 0.0083 \\
\hline RP3_412A9.17 & -8.2 & $0.00027(1.1 \mathrm{e}-08-6.3)$ & -1.6 & 0.11 \\
\hline EGFR_AS1 & 0.73 & $2.1(1.6-2.8)$ & 5 & $7.10 \mathrm{E}-07$ \\
\hline RP11_92F20.1 & -0.89 & $0.41(0.12-1.4)$ & -1.4 & 0.16 \\
\hline RP11_338L22.2 & -2.8 & $0.06(0.0051-0.71)$ & -2.2 & 0.026 \\
\hline XXbac_BPG299F13.17 & -0.62 & $0.54(0.36-0.79)$ & -3.1 & 0.0017 \\
\hline
\end{tabular}

Table 5 Univariate and stepwise multivariate regression analysis of 13-OS-related signature and clinical factors in BC.

\begin{tabular}{|c|c|c|c|c|c|c|c|c|c|}
\hline & Univariate & & & & & Multivariate & & & \\
\hline Characteristic & Coefficient & $\begin{array}{l}\mathrm{HR}(95 \% \mathrm{Cl} \\
\text { for HR) }\end{array}$ & $\begin{array}{l}\text { Wald. } \\
\text { test }\end{array}$ & $\mathbf{z}$ & $\begin{array}{l}P \text {. } \\
\text { value }\end{array}$ & Coefficient & $\begin{array}{l}\mathrm{HR}(95 \% \mathrm{Cl} \\
\text { for HR) }\end{array}$ & $\mathbf{z}$ & $\begin{array}{l}P \text {. } \\
\text { value }\end{array}$ \\
\hline Age & 0.41 & $1.5(0.68-3.4)$ & 1 & 1 & 0.31 & NA & NA & NA & NA \\
\hline $\mathrm{BMI}$ & -0.0097 & $\begin{array}{l}0.99(0.93- \\
1.1)\end{array}$ & 0.1 & -0.31 & 0.75 & NA & NA & NA & NA \\
\hline Gender & 0.38 & $1.5(0.78-2.8)$ & 1.4 & 1.2 & 0.24 & NA & NA & NA & NA \\
\hline$M$ & 1.2 & $3.3(1.3-8.3)$ & 6.1 & 2.5 & 0.014 & 0.72 & $\begin{array}{l}2.1(0.64- \\
6.6)\end{array}$ & 1.2 & 0.23 \\
\hline $\mathrm{N}$ & 0.34 & $1.4(1-1.9)$ & 4.5 & 2.1 & 0.035 & 0.024 & $1(0.56-1.9)$ & 0.08 & 0.94 \\
\hline $\begin{array}{l}\text { Pathologic } \\
\text { Stage }\end{array}$ & 0.43 & $1.5(1.1-2.2)$ & 5 & 2.2 & 0.025 & 0.25 & $\begin{array}{l}1.3(0.61- \\
2.7)\end{array}$ & 0.66 & 0.51 \\
\hline $\begin{array}{l}\text { Prior } \\
\text { malignancy }\end{array}$ & -0.042 & $\begin{array}{l}0.96(0.53- \\
1.7)\end{array}$ & 0.02 & -0.14 & 0.89 & NA & NA & NA & NA \\
\hline Risk Score & 0.29 & $1.3(1.2-1.5)$ & 17 & 4.2 & $\begin{array}{l}2.90 \mathrm{E}- \\
05\end{array}$ & 0.29 & $\begin{array}{l}1.3(1.2- \\
1.5)\end{array}$ & 4 & $\begin{array}{l}6.20 \mathrm{E}- \\
05\end{array}$ \\
\hline $\mathrm{T}$ & 0.42 & $1.5(1-2.3)$ & 4 & 2 & 0.047 & 0.15 & $\begin{array}{l}1.2(0.66- \\
2.1)\end{array}$ & 0.53 & 0.6 \\
\hline $\begin{array}{l}\text { Treatment or } \\
\text { therapy }\end{array}$ & -0.52 & $\begin{array}{l}0.59(0.31- \\
1.1)\end{array}$ & 2.4 & -1.6 & 0.12 & NA & NA & NA & NA \\
\hline
\end{tabular}

Table 6 Top $10 \mathrm{GO}$ items between high-risk group and low-risk groups. 


\begin{tabular}{|c|c|c|c|c|c|c|c|}
\hline Category & ID & Description & $\begin{array}{l}\text { Set } \\
\text { Size }\end{array}$ & $\begin{array}{l}\text { Enrichment } \\
\text { Score }\end{array}$ & NES & $P$ value & $P$. adjust \\
\hline GO_BP & GO:0000278 & mitotic cell cycle & 992 & -0.464724267 & -1.3614549 & 0.001001001 & 0.061778905 \\
\hline GO_BP & GO:0016071 & $\begin{array}{l}\text { mRNA metabolic } \\
\text { process }\end{array}$ & 848 & -0.542660019 & -1.587106501 & 0.001001001 & 0.061778905 \\
\hline GO_BP & GO:0006259 & $\begin{array}{l}\text { DNA metabolic } \\
\text { process }\end{array}$ & 952 & -0.545942243 & -1.598313641 & 0.001002004 & 0.061778905 \\
\hline GO_BP & GO:0010608 & $\begin{array}{l}\text { posttranscriptional } \\
\text { regulation of gene } \\
\text { expression }\end{array}$ & 988 & -0.437354846 & -1.280957399 & 0.001002004 & 0.061778905 \\
\hline GO_BP & G0:0032446 & $\begin{array}{l}\text { protein } \\
\text { modification by } \\
\text { small protein } \\
\text { conjugation }\end{array}$ & 863 & -0.488265611 & -1.427585831 & 0.001003009 & 0.061778905 \\
\hline GO_BP & GO:1903047 & $\begin{array}{l}\text { mitotic cell cycle } \\
\text { process }\end{array}$ & 849 & -0.47915529 & -1.400713629 & 0.001003009 & 0.061778905 \\
\hline GO_BP & GO:0006974 & $\begin{array}{l}\text { cellular response } \\
\text { to DNA damage } \\
\text { stimulus }\end{array}$ & 808 & -0.526701319 & -1.539454663 & 0.001005025 & 0.061778905 \\
\hline GO_BP & GO:0007017 & $\begin{array}{l}\text { microtubule-based } \\
\text { process }\end{array}$ & 735 & -0.465135709 & -1.357317291 & 0.001005025 & 0.061778905 \\
\hline GO_BP & GO:0010564 & $\begin{array}{l}\text { regulation of cell } \\
\text { cycle process }\end{array}$ & 761 & -0.453381982 & -1.323138862 & 0.001006036 & 0.061778905 \\
\hline GO_BP & GO:0016567 & $\begin{array}{l}\text { protein } \\
\text { ubiquitination }\end{array}$ & 781 & -0.484549462 & -1.415369216 & 0.001006036 & 0.061778905 \\
\hline GO_CC & GO:0044429 & mitochondrial part & 989 & -0.502561227 & -1.469216881 & 0.001 & 0.024793568 \\
\hline GO_CC & GO:0005694 & chromosome & 960 & -0.591508504 & -1.727406672 & 0.001003009 & 0.024793568 \\
\hline GO_CC & GO:0044427 & chromosomal part & 839 & -0.581404731 & -1.693270033 & 0.001003009 & 0.024793568 \\
\hline GO_CC & GO:0016604 & nuclear body & 756 & -0.532684555 & -1.549009555 & 0.001007049 & 0.024793568 \\
\hline GO_CC & GO:1990234 & $\begin{array}{l}\text { transferase } \\
\text { complex }\end{array}$ & 760 & -0.54196285 & -1.575933532 & 0.001008065 & 0.024793568 \\
\hline GO_CC & GO:0005740 & $\begin{array}{l}\text { mitochondrial } \\
\text { envelope }\end{array}$ & 700 & -0.474912399 & -1.377157665 & 0.001011122 & 0.024793568 \\
\hline GO_CC & G0:0031966 & $\begin{array}{l}\text { mitochondrial } \\
\text { membrane }\end{array}$ & 659 & -0.47798788 & -1.383462124 & 0.001011122 & 0.024793568 \\
\hline GO_CC & GO:0005815 & $\begin{array}{l}\text { microtubule } \\
\text { organizing center }\end{array}$ & 717 & -0.496117777 & -1.438036473 & 0.001012146 & 0.024793568 \\
\hline GO_CC & GO:0000228 & $\begin{array}{l}\text { nuclear } \\
\text { chromosome }\end{array}$ & 536 & -0.560614936 & -1.609688185 & 0.00102145 & 0.024793568 \\
\hline GO_CC & G0:0019866 & $\begin{array}{l}\text { organelle inner } \\
\text { membrane }\end{array}$ & 499 & -0.529177603 & -1.514318611 & 0.001027749 & 0.024793568 \\
\hline GO_MF & G0:0003690 & $\begin{array}{l}\text { double-stranded } \\
\text { DNA binding }\end{array}$ & 951 & -0.438323917 & -1.285738833 & 0.001002004 & 0.078819444 \\
\hline GO_MF & GO:0003682 & chromatin binding & 506 & -0.485755154 & -1.398894504 & 0.00101833 & 0.078819444 \\
\hline GO_MF & GO:0019787 & $\begin{array}{l}\text { ubiquitin-like } \\
\text { protein transferase } \\
\text { activity }\end{array}$ & 394 & -0.50980879 & -1.458055509 & 0.001033058 & 0.078819444 \\
\hline
\end{tabular}




\begin{tabular}{|c|c|c|c|c|c|c|c|}
\hline GO_MF & GO:0004842 & $\begin{array}{l}\text { ubiquitin-protein } \\
\text { transferase } \\
\text { activity }\end{array}$ & 369 & -0.519072957 & -1.480260991 & 0.00104712 & 0.078819444 \\
\hline GO_MF & G0:0140098 & $\begin{array}{l}\text { catalytic activity, } \\
\text { acting on RNA }\end{array}$ & 344 & -0.64201376 & -1.825584896 & 0.001053741 & 0.078819444 \\
\hline GO_MF & GO:0016747 & $\begin{array}{l}\text { transferase } \\
\text { activity, } \\
\text { transferring acyl } \\
\text { groups other than } \\
\text { amino-acyl groups }\end{array}$ & 222 & -0.544216869 & -1.510691791 & 0.001092896 & 0.078819444 \\
\hline GO_MF & G0:0016741 & $\begin{array}{l}\text { transferase } \\
\text { activity, } \\
\text { transferring one- } \\
\text { carbon groups }\end{array}$ & 215 & -0.563259955 & -1.556126762 & 0.00110011 & 0.078819444 \\
\hline GO_MF & GO:0008168 & $\begin{array}{l}\text { methyltransferase } \\
\text { activity }\end{array}$ & 204 & -0.57625549 & -1.582657961 & 0.001103753 & 0.078819444 \\
\hline GO_MF & G0:0140097 & $\begin{array}{l}\text { catalytic activity, } \\
\text { acting on DNA }\end{array}$ & 200 & -0.667001877 & -1.831792815 & 0.001103753 & 0.078819444 \\
\hline GO_MF & GO:0004518 & nuclease activity & 191 & -0.581259246 & -1.591485284 & 0.001104972 & 0.078819444 \\
\hline
\end{tabular}

Table 7 Top 10 KEGG pathway enrichment between high-risk and low-risk groups.

\begin{tabular}{|lllllll|}
\hline ID & Description & Set Size & Enrichment Score & NES & $P$ value & $P$. adjust \\
\hline hsa05168 & Herpes simplex virus 1 infection & 488 & -0.6446174 & -1.842130 & 0.0010183 & 0.0351334 \\
\hline hsa03013 & RNA transport & 181 & -0.6186630 & -1.666905 & 0.0011148 & 0.0351334 \\
\hline hsa03040 & Spliceosome & 150 & -0.6288256 & -1.678070 & 0.0011312 & 0.0351334 \\
\hline hsa03015 & mRNA surveillance pathway & 98 & -0.6341924 & -1.619593 & 0.0011806 & 0.0351334 \\
\hline hsa03008 & $\begin{array}{l}\text { Ribosome biogenesis in } \\
\text { eukaryotes }\end{array}$ & 100 & -0.6383869 & -1.634230 & 0.0011834 & 0.0351334 \\
\hline hsa03460 & Fanconi anemia pathway & 51 & -0.7493155 & -1.754771 & 0.0012626 & 0.0351334 \\
\hline hsa03440 & Homologous recombination & 41 & -0.7138885 & -1.630394 & 0.0012739 & 0.0351334 \\
\hline hsa03030 & DNA replication & 36 & -0.7239130 & -1.620366 & 0.0013072 & 0.0351334 \\
\hline hsa03410 & Base excision repair & 32 & -0.7507609 & -1.642526 & 0.0013280 & 0.0351334 \\
\hline hsa00640 & Propanoate metabolism & 33 & -0.6984884 & -1.535068 & 0.0026455 & 0.0351334 \\
\hline
\end{tabular}

Table 8 Top 10 Reactome pathway enrichment between high-risk and low-risk groups. 


\begin{tabular}{|c|c|c|c|c|c|c|}
\hline ID & Description & $\begin{array}{l}\text { Set } \\
\text { Size }\end{array}$ & $\begin{array}{l}\text { Enrichment } \\
\text { Score }\end{array}$ & NES & $P$ value & $P$. adjust \\
\hline $\begin{array}{l}\text { R-HSA- } \\
8953854\end{array}$ & Metabolism of RNA & 654 & -0.5878868 & -1.709269 & 0.0010081 & 0.0207553 \\
\hline $\begin{array}{l}\text { R-HSA- } \\
1640170\end{array}$ & Cell Cycle & 580 & -0.6190954 & -1.795344 & 0.0010101 & 0.0207553 \\
\hline $\begin{array}{l}\text { R-HSA- } \\
69278\end{array}$ & Cell Cycle, Mitotic & 476 & -0.6098167 & -1.754112 & 0.0010225 & 0.0207553 \\
\hline $\begin{array}{l}\text { R-HSA- } \\
3700989\end{array}$ & Transcriptional Regulation by TP53 & 358 & -0.5412421 & -1.535369 & 0.0010471 & 0.0207553 \\
\hline $\begin{array}{l}\text { R-HSA- } \\
68886\end{array}$ & M Phase & 333 & -0.6182648 & -1.751180 & 0.0010482 & 0.0207553 \\
\hline $\begin{array}{l}\text { R-HSA- } \\
73894\end{array}$ & DNA Repair & 281 & -0.6328865 & -1.774354 & 0.0010650 & 0.0207553 \\
\hline $\begin{array}{l}\text { R-HSA- } \\
69620\end{array}$ & Cell Cycle Checkpoints & 259 & -0.6739822 & -1.879255 & 0.0010811 & 0.0207553 \\
\hline $\begin{array}{l}\text { R-HSA- } \\
5688426\end{array}$ & Deubiquitination & 262 & -0.5316360 & -1.482592 & 0.0010823 & 0.0207553 \\
\hline $\begin{array}{l}\text { R-HSA- } \\
72203\end{array}$ & $\begin{array}{l}\text { Processing of Capped Intron- } \\
\text { Containing Pre-mRNA }\end{array}$ & 240 & -0.6935057 & -1.927120 & 0.0010929 & 0.0207553 \\
\hline $\begin{array}{l}\text { R-HSA- } \\
3247509\end{array}$ & Chromatin modifying enzymes & 206 & -0.6358033 & -1.757258 & 0.0010929 & 0.0207553 \\
\hline
\end{tabular}

Table 9 Top 30 immune-related GO items between high-risk and low-risk groups. 


\begin{tabular}{|c|c|c|c|c|c|c|c|}
\hline Category & ID & Description & $\begin{array}{l}\text { Set } \\
\text { Size }\end{array}$ & $\begin{array}{l}\text { Enrichment } \\
\text { Score }\end{array}$ & NES & $P$ value & $P$. adjust \\
\hline GO_BP & GO:0061844 & $\begin{array}{l}\text { antimicrobial } \\
\text { humoral immune } \\
\text { response } \\
\text { mediated by } \\
\text { antimicrobial } \\
\text { peptide }\end{array}$ & 64 & 0.656427085 & 1.880885659 & 0.004545455 & 0.061778905 \\
\hline GO_BP & GO:0002920 & $\begin{array}{l}\text { regulation of } \\
\text { humoral immune } \\
\text { response }\end{array}$ & 72 & 0.692362073 & 1.998668651 & 0.004784689 & 0.061778905 \\
\hline GO_BP & GO:0002698 & $\begin{array}{l}\text { negative } \\
\text { regulation of } \\
\text { immune effector } \\
\text { process }\end{array}$ & 119 & 0.479991273 & 1.50663113 & 0.006410256 & 0.061778905 \\
\hline GO_BP & GO:0061760 & $\begin{array}{l}\text { antifungal innate } \\
\text { immune response }\end{array}$ & 6 & 0.944371109 & 1.671379401 & 0.006644518 & 0.061778905 \\
\hline GO_BP & GO:0002825 & $\begin{array}{l}\text { regulation of T- } \\
\text { helper } 1 \text { type } \\
\text { immune response }\end{array}$ & 27 & 0.694207786 & 1.694245404 & 0.007194245 & 0.061778905 \\
\hline GO_BP & GO:0050777 & $\begin{array}{l}\text { negative } \\
\text { regulation of } \\
\text { immune response }\end{array}$ & 149 & 0.429811218 & 1.37517549 & 0.0078125 & 0.061778905 \\
\hline GO_BP & GO:0002455 & $\begin{array}{l}\text { humoral immune } \\
\text { response } \\
\text { mediated by } \\
\text { circulating } \\
\text { immunoglobulin }\end{array}$ & 46 & 0.597003903 & 1.63760526 & 0.008130081 & 0.061778905 \\
\hline GO_BP & GO:0002460 & $\begin{array}{l}\text { adaptive immune } \\
\text { response based on } \\
\text { somatic } \\
\text { recombination of } \\
\text { immune receptors } \\
\text { built from } \\
\text { immunoglobulin } \\
\text { superfamily } \\
\text { domains }\end{array}$ & 249 & 0.41445012 & 1.404280462 & 0.012195122 & 0.075469812 \\
\hline GO_BP & GO:0006959 & $\begin{array}{l}\text { humoral immune } \\
\text { response }\end{array}$ & 242 & 0.596316105 & 2.011824756 & 0.012195122 & 0.075469812 \\
\hline GO_BP & GO:0002566 & $\begin{array}{l}\text { somatic } \\
\text { diversification of } \\
\text { immune receptors } \\
\text { via somatic } \\
\text { mutation }\end{array}$ & 14 & -0.746642029 & -1.416986547 & 0.023611111 & 0.105846068 \\
\hline GO_BP & G0:0002367 & $\begin{array}{l}\text { cytokine } \\
\text { production } \\
\text { involved in } \\
\text { immune response }\end{array}$ & 100 & 0.460689547 & 1.394236368 & 0.023809524 & 0.105846068 \\
\hline GO_BP & GO:0002697 & $\begin{array}{l}\text { regulation of } \\
\text { immune effector } \\
\text { process }\end{array}$ & 382 & 0.434712763 & 1.524381063 & 0.024390244 & 0.107845588 \\
\hline GO_BP & GO:0002313 & $\begin{array}{l}\text { mature B cell } \\
\text { differentiation } \\
\text { involved in } \\
\text { immune response }\end{array}$ & 19 & 0.752170817 & 1.698308816 & 0.025362319 & 0.110685264 \\
\hline GO_BP & GO:0002828 & $\begin{array}{l}\text { regulation of type } \\
2 \text { immune }\end{array}$ & 30 & 0.612415889 & 1.523211012 & 0.028776978 & 0.11939051 \\
\hline
\end{tabular}

Page 23/32 
response

\begin{tabular}{|c|c|c|c|c|c|c|c|}
\hline GO_BP & GO:0002250 & $\begin{array}{l}\text { adaptive immune } \\
\text { response }\end{array}$ & 399 & 0.374636813 & 1.314964677 & 0.03125 & 0.125055212 \\
\hline GO_BP & GO:0016064 & $\begin{array}{l}\text { immunoglobulin } \\
\text { mediated immune } \\
\text { response }\end{array}$ & 111 & 0.426648404 & 1.325134841 & 0.031446541 & 0.12561978 \\
\hline GO_BP & G0:0042092 & $\begin{array}{l}\text { type } 2 \text { immune } \\
\text { response }\end{array}$ & 35 & 0.570714804 & 1.476162204 & 0.033210332 & 0.130132589 \\
\hline GO_BP & GO:0002683 & $\begin{array}{l}\text { negative } \\
\text { regulation of } \\
\text { immune system } \\
\text { process }\end{array}$ & 433 & 0.473489834 & 1.663316675 & 0.034482759 & 0.132547218 \\
\hline
\end{tabular}

\begin{tabular}{|c|c|c|c|c|c|c|c|}
\hline GO_BP & GO:0002699 & $\begin{array}{l}\text { positive regulation } \\
\text { of immune } \\
\text { effector process }\end{array}$ & 206 & 0.389608877 & 1.276417783 & 0.034482759 & 0.132547218 \\
\hline GO_BP & G0:0042088 & $\begin{array}{l}\text { T-helper } 1 \text { type } \\
\text { immune response }\end{array}$ & 42 & 0.548051796 & 1.473951212 & 0.034749035 & 0.133288 \\
\hline GO_BP & GO:0002700 & $\begin{array}{l}\text { regulation of } \\
\text { production of } \\
\text { molecular } \\
\text { mediator of } \\
\text { immune response }\end{array}$ & 133 & 0.411048764 & 1.295197795 & 0.035714286 & 0.135783226 \\
\hline Category & G0:0002283 & $\begin{array}{l}\text { neutrophil } \\
\text { activation involved } \\
\text { in immune } \\
\text { response }\end{array}$ & 479 & 0.545581181 & 1.977918089 & 0.037037037 & 0.137241536 \\
\hline GO_BP & GO:0002275 & $\begin{array}{l}\text { myeloid cell } \\
\text { activation involved } \\
\text { in immune } \\
\text { response }\end{array}$ & 533 & 0.539350874 & 1.967939907 & 0.038461538 & 0.139552078 \\
\hline GO_BP & GO:0002757 & $\begin{array}{l}\text { immune response- } \\
\text { activating signal } \\
\text { transduction }\end{array}$ & 515 & 0.317517933 & 1.149727314 & 0.041666667 & 0.145248172 \\
\hline GO_BP & GO:0002718 & $\begin{array}{l}\text { regulation of } \\
\text { cytokine } \\
\text { production } \\
\text { involved in } \\
\text { immune response }\end{array}$ & 82 & 0.465493608 & 1.367849793 & 0.042553191 & 0.148053731 \\
\hline GO_BP & GO:0002253 & $\begin{array}{l}\text { activation of } \\
\text { immune response }\end{array}$ & 595 & 0.3727582 & 1.359115478 & 0.045454545 & 0.153893192 \\
\hline GO_BP & GO:0002764 & $\begin{array}{l}\text { immune response- } \\
\text { regulating } \\
\text { signaling pathway }\end{array}$ & 548 & 0.32806093 & 1.187034741 & 0.045454545 & 0.153893192 \\
\hline GO_BP & GO:0002440 & $\begin{array}{l}\text { production of } \\
\text { molecular } \\
\text { mediator of } \\
\text { immune response }\end{array}$ & 193 & 0.368868951 & 1.219083215 & 0.047169811 & 0.15751317 \\
\hline GO_BP & GO:0002720 & $\begin{array}{l}\text { positive regulation } \\
\text { of cytokine } \\
\text { production } \\
\text { involved in } \\
\text { immune response }\end{array}$ & 52 & 0.471727597 & 1.311127536 & 0.049180328 & 0.161732766 \\
\hline
\end{tabular}

\section{Figures}




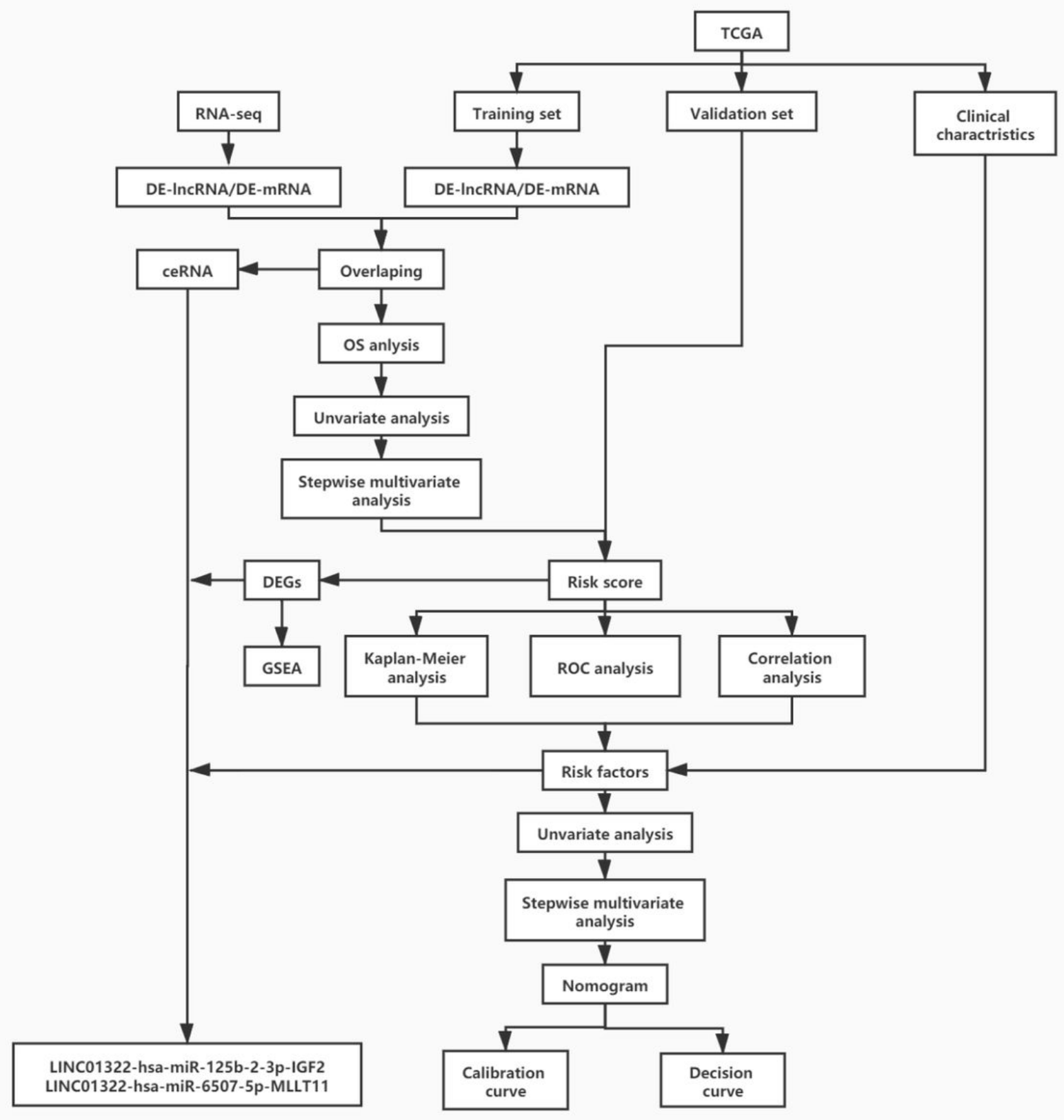

Figure 1

Flowchart illustrated the study design and analysis analytical processing. 


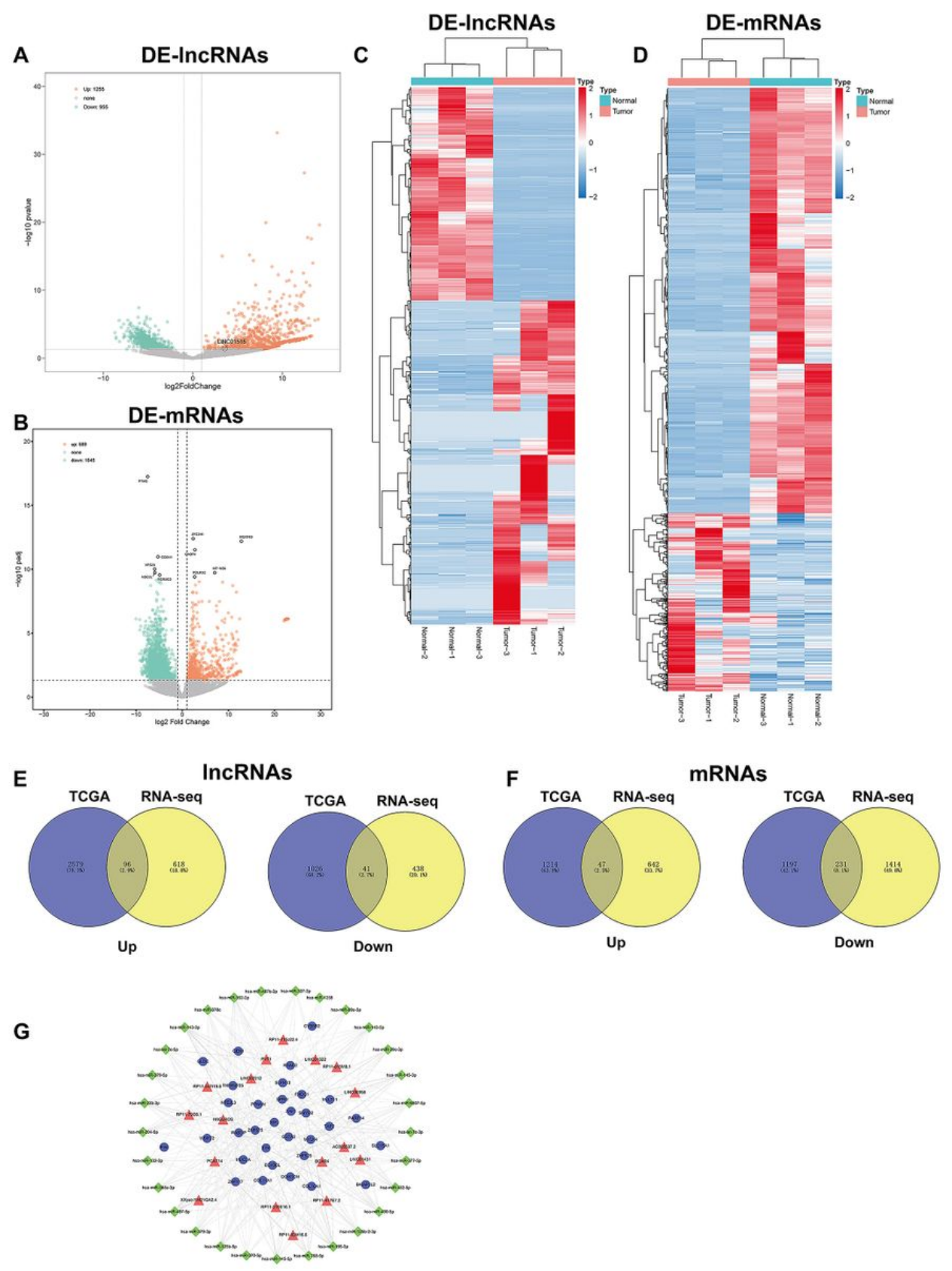

Figure 2

Identification of DE-IncRNA and DE-mRNA and construction of ceRNA network in BC A, B The volcano plot of DE-IncRNAs and DE-mRNAs between three paired bladder cancer samples and adjacent normal samples. C, D The heatmap of DE-IncRNAs and DE-mRNAs between three paired bladder cancer samples and adjacent normal samples. E, F The Venn of DE-IncRNAs and DEmRNAs by overlapping between RNA-seq data and TCGA data. G The IncRNA-miRNA-mRNA ceRNA network based on overlapped DE-IncRNAs and DE-mRNAs 


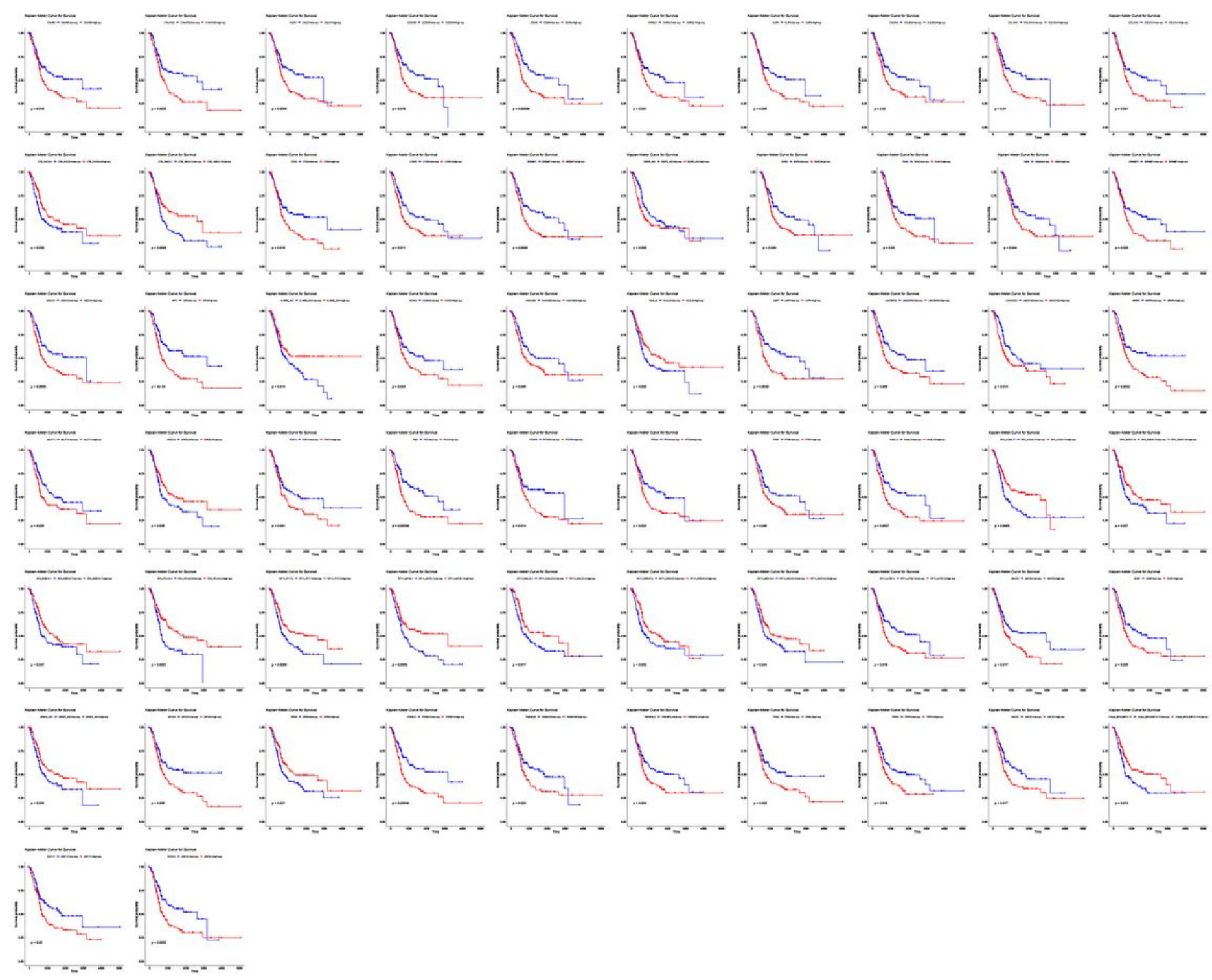

Figure 3

Kaplan-Meier curves exhibited 62 significant survival-related DE-mRNAs and DE-IncRNAs in BC. 


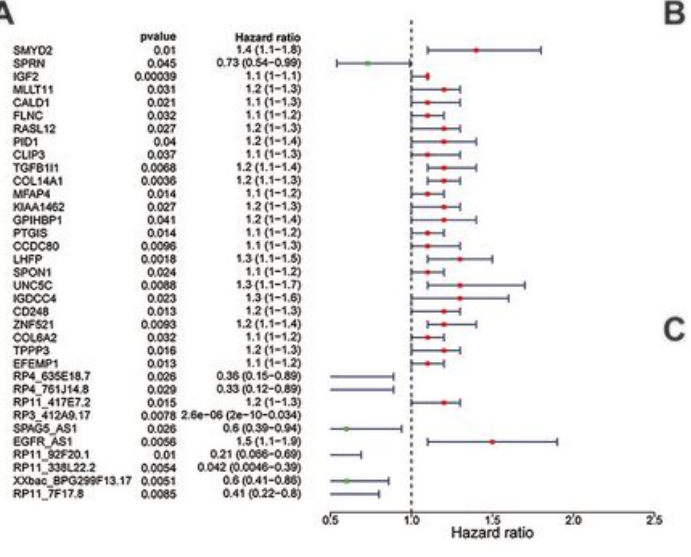

B

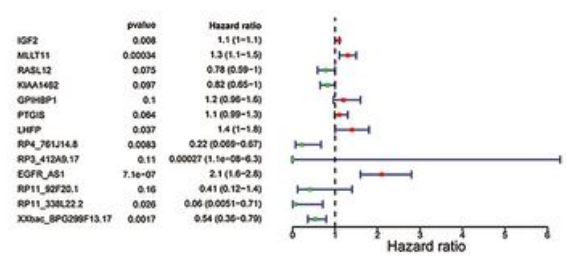

C Taining set

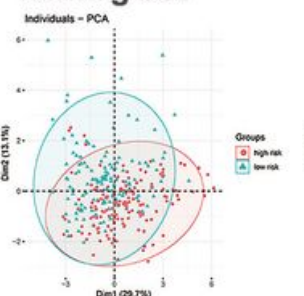

Validation set

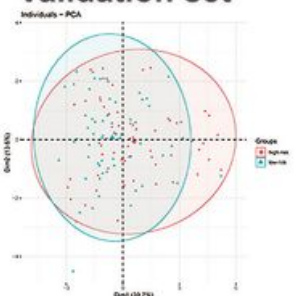

D

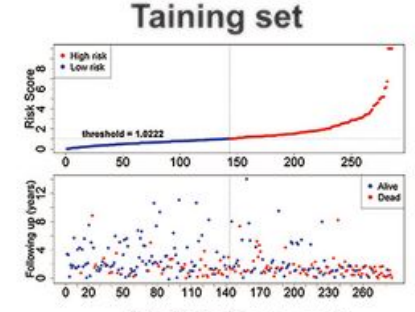

Validation set
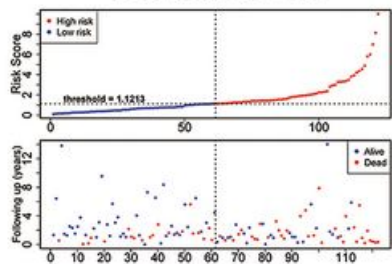

E Taining set

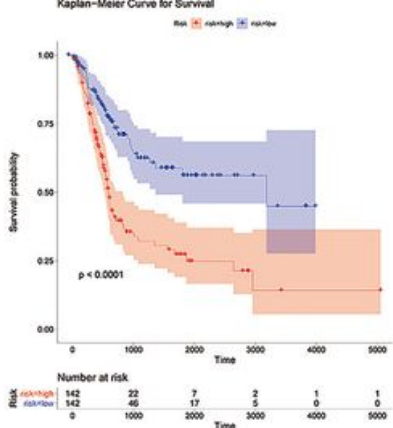

Validation set

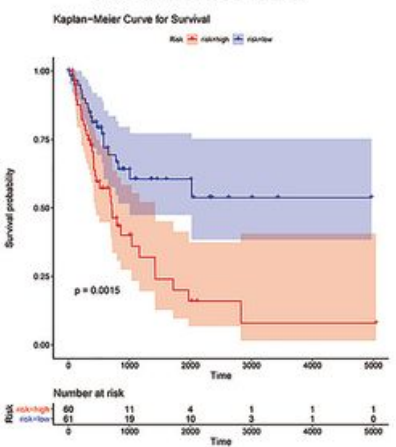

F Taining set

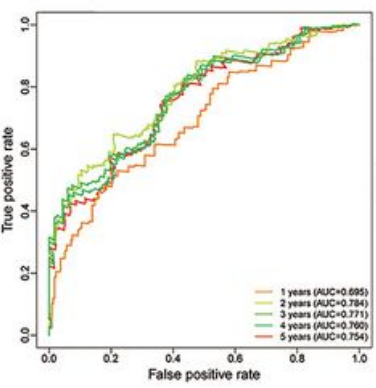

Validation set

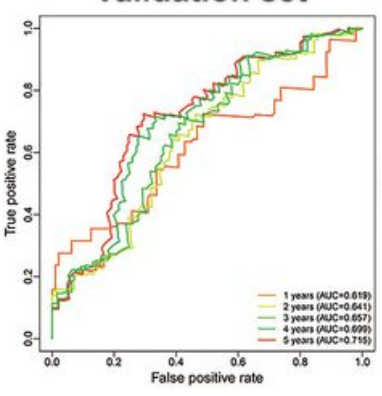

G

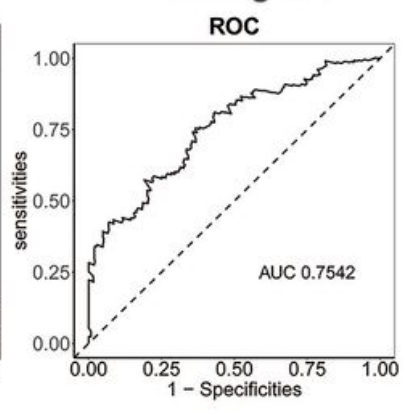

Validation set

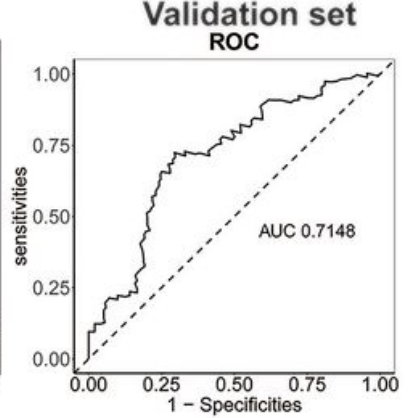

H
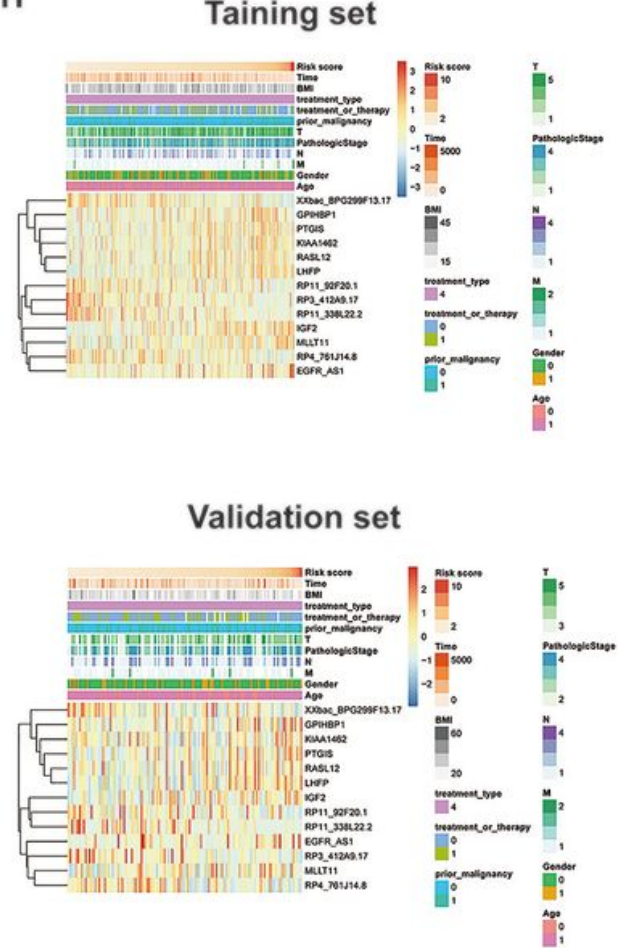

\section{Figure 4}

Screening of 13-OS-related signature from BC based TCGA database. A The forest plots of 35 variates associated to OS in training set. B The forest plots of 13-OS-related signature associated to OS in training set. C The PCA plot shown the difference between high-risk and low-risk groups in training set and validation set. D Up: The risk score distribution, and Bottom: The survival statues between high-risk and low-risk groups in training set and validation set. E Kaplan-Meier curves for high-risk and low-risk bladder cancer based on 13-OS-related signature in training set and validation set. F Time-dependent ROC curves illustrated the predictive of the 1, 2, 3, 4, 5-years based on 13-OS-related signature in training set and validation set. G Timedependent ROC curves illustrated the predictive of the 5-years based on 13-0S-related signature in training set and validation set. H The heatmap of 13-OS-related signature expression and association to clinical features in training set and validation set. 
A

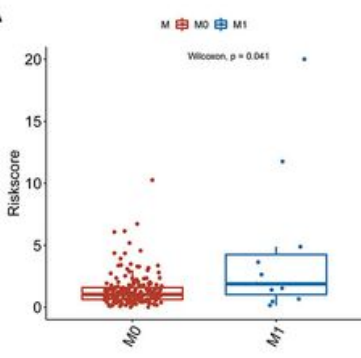

C kspan-Neerec Cune tor Sunvial
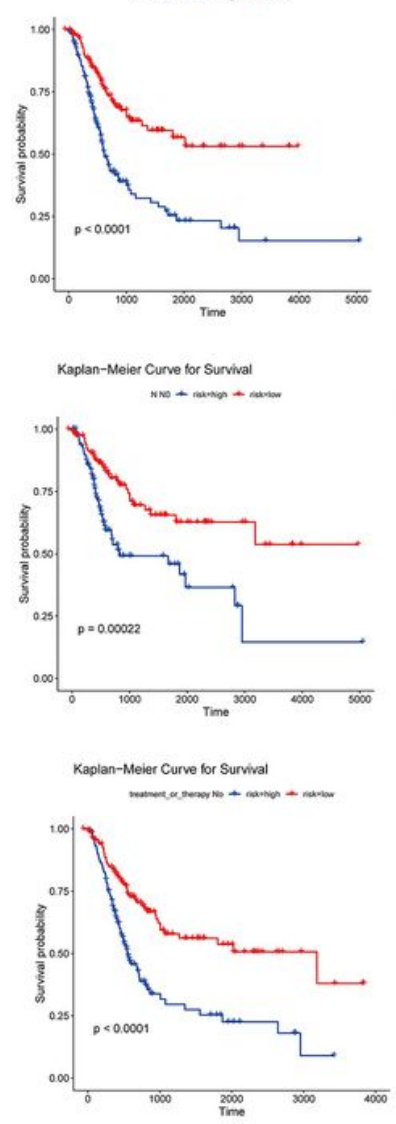
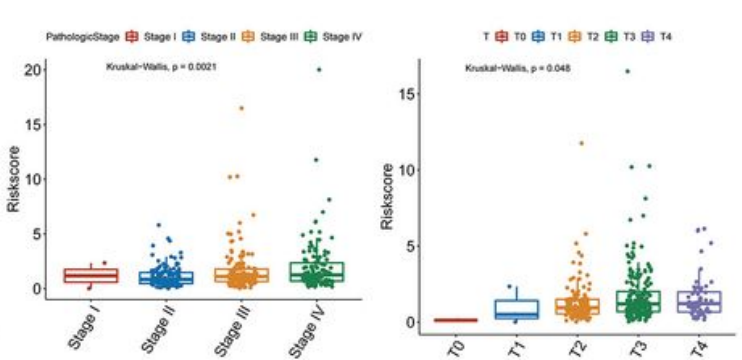

Kaplan-Meier Curve for Survival

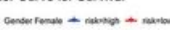

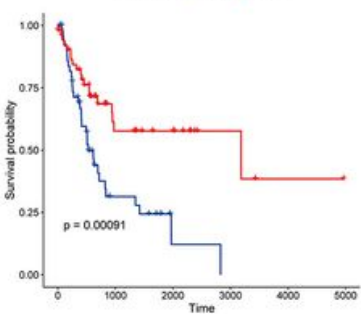

D Kaplan-Meler Cunve tor Survival
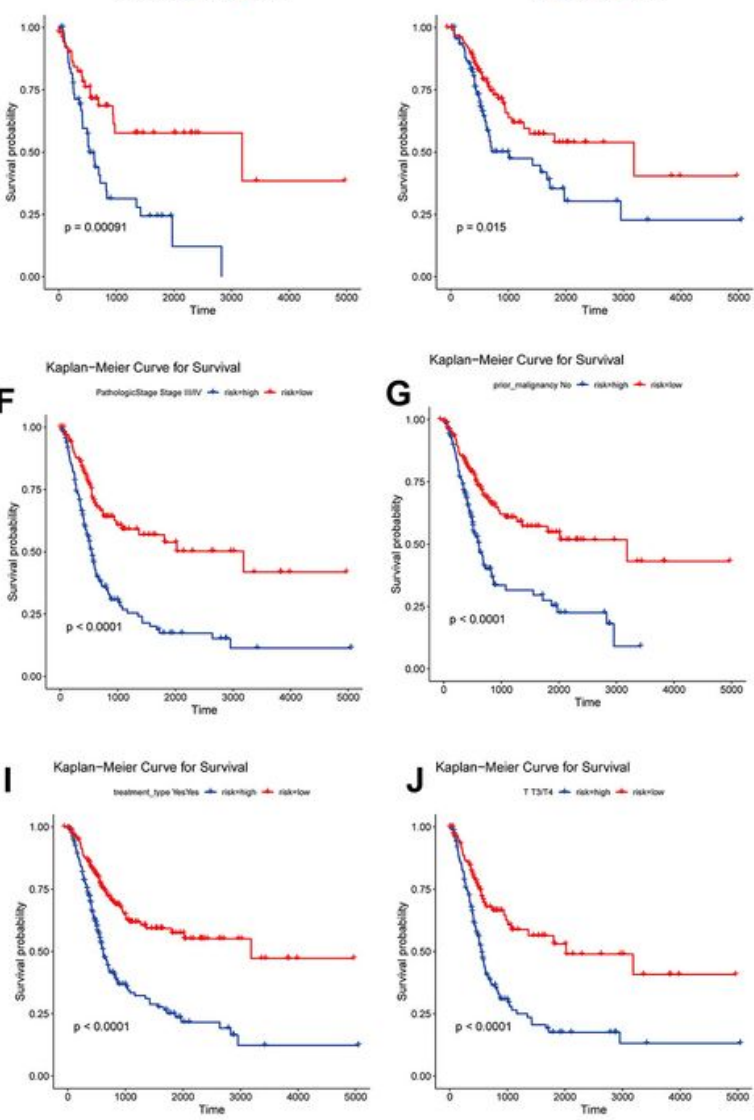

B
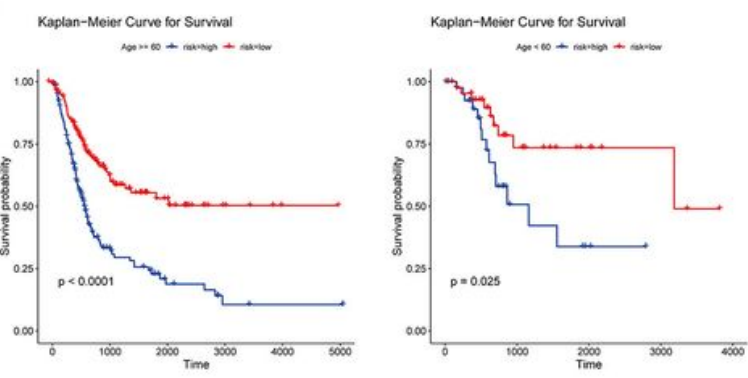

Kaplan-Meier Curve for Survival

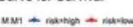

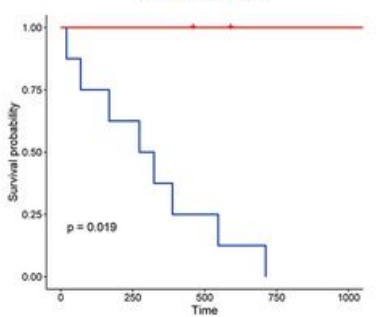

E Kaplan-Meler Curve tor Survival
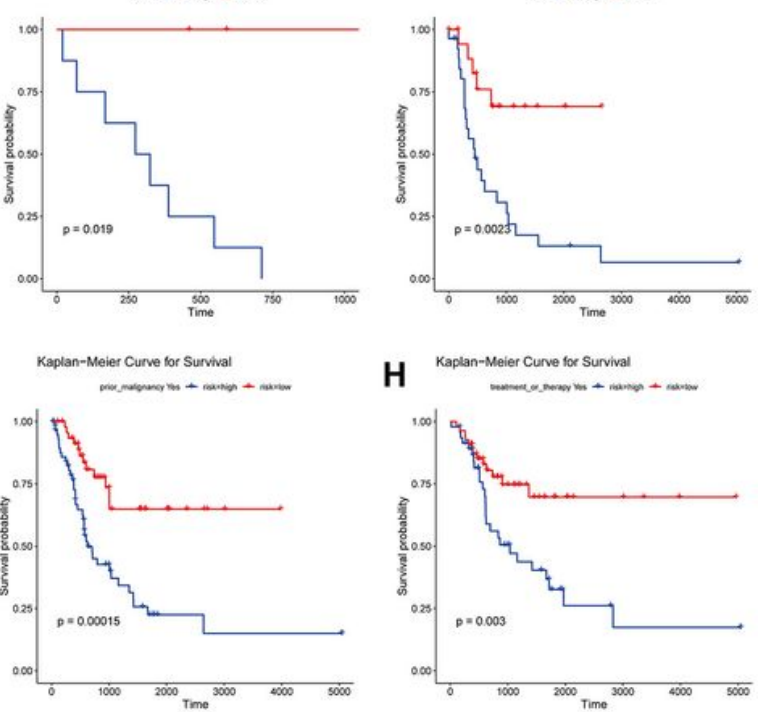

\section{Figure 5}

Association between risk score and clinical characteristics in BC. A The box plots shown association between risk score and M stages, pathologic stages, and N stages in entire datasets. B-J Kaplan-Meier curves exhibited association between risk score and age stratification with 60 years, gender stratification, $M / N / T$ stages stratification, pathologic stages, prior malignancy statues, and treatment or therapy types in entire sets.
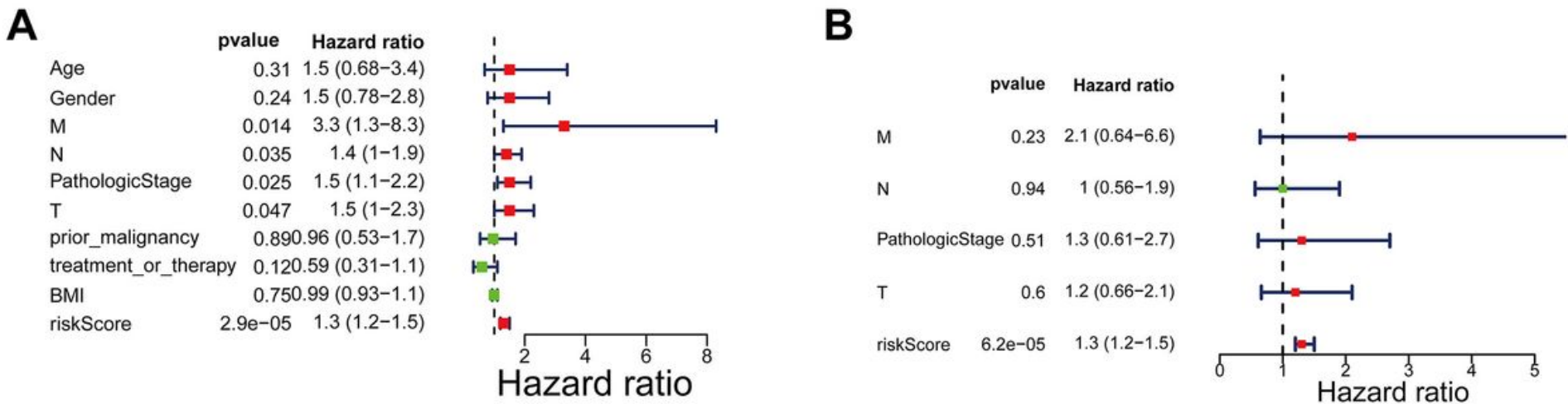


\section{Figure 6}

Identification and validation of the 13-OS-related signature in BC patients. A The forest plot of 13-OS-related signature and clinical risk factors in the entire datasets. $B$ The forest plot of 13-OS-related signature and $\mathrm{T} / \mathrm{M} / \mathrm{N}$ stages and pathological stage in the entire datasets.

A

Points

M

N

PathologicStage

T

riskScore

Total Points

Linear Predictor

Median Survival Tim

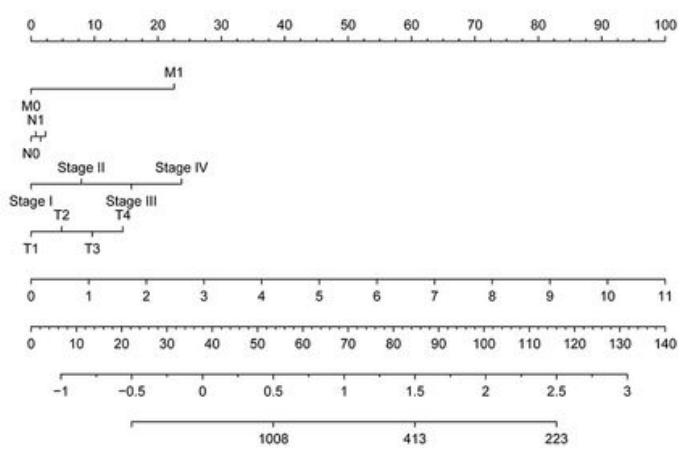

B

Points

M

N

PathologicStage

$T$

riskScore

Total Points

Linear Predictor

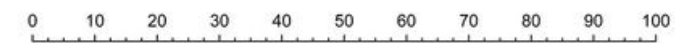

3-year Survival Probability

5-year Survival Probability

C

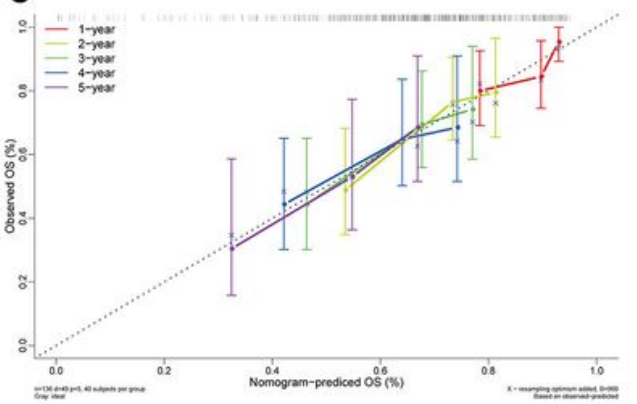

D

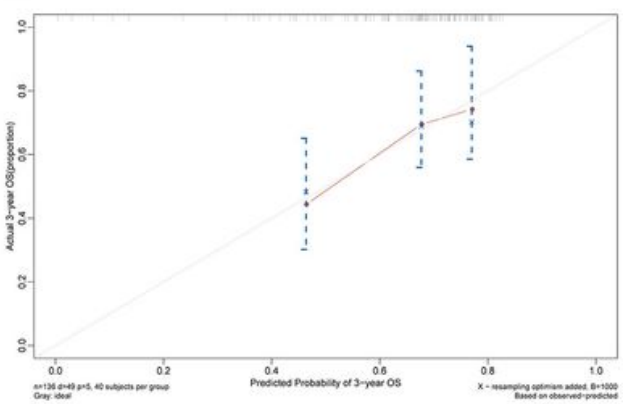

\begin{tabular}{llllllll}
\hline 0.8 & 0.7 & 0.6 & 0.5 & 0.4 & 0.3 & 0.2 & 0.1
\end{tabular}

$\begin{array}{llllllll}0.7 & 0.6 & 0.5 & 0.4 & 0.3 & 0.2 & 0.1\end{array}$

M1

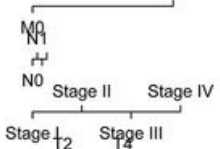

T1 T3

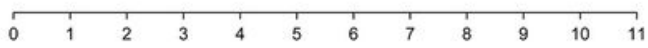

\begin{tabular}{lllllllllllllll}
\hline 0 & 10 & 20 & 30 & 40 & 50 & 60 & 70 & 80 & 90 & 100 & 110 & 120 & 130 & 140
\end{tabular}

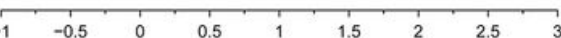

E

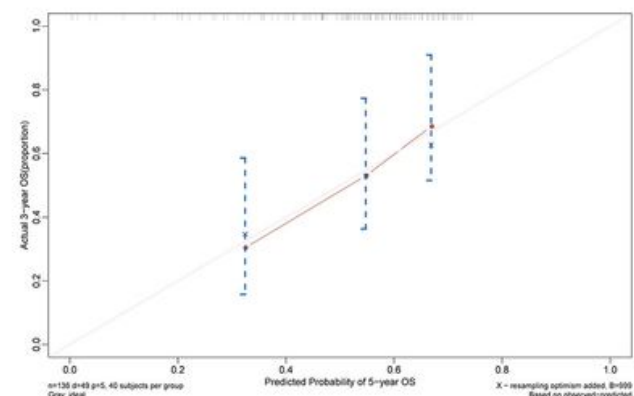

Figure 7

Construction and validation of a nomogram for prognostic prediction in BC. A, B The nomogram for predicating median survival time, 3- and 5-years survival time. $\mathrm{C}$ The C-index and calibration plots shown discrimination and calibration ability of nomogram for 1, 2, 3, 4, 5-years survival time. D, E The C-index and calibration plots shown discrimination and calibration ability of nomogram for 3- and 5-years survival time. 

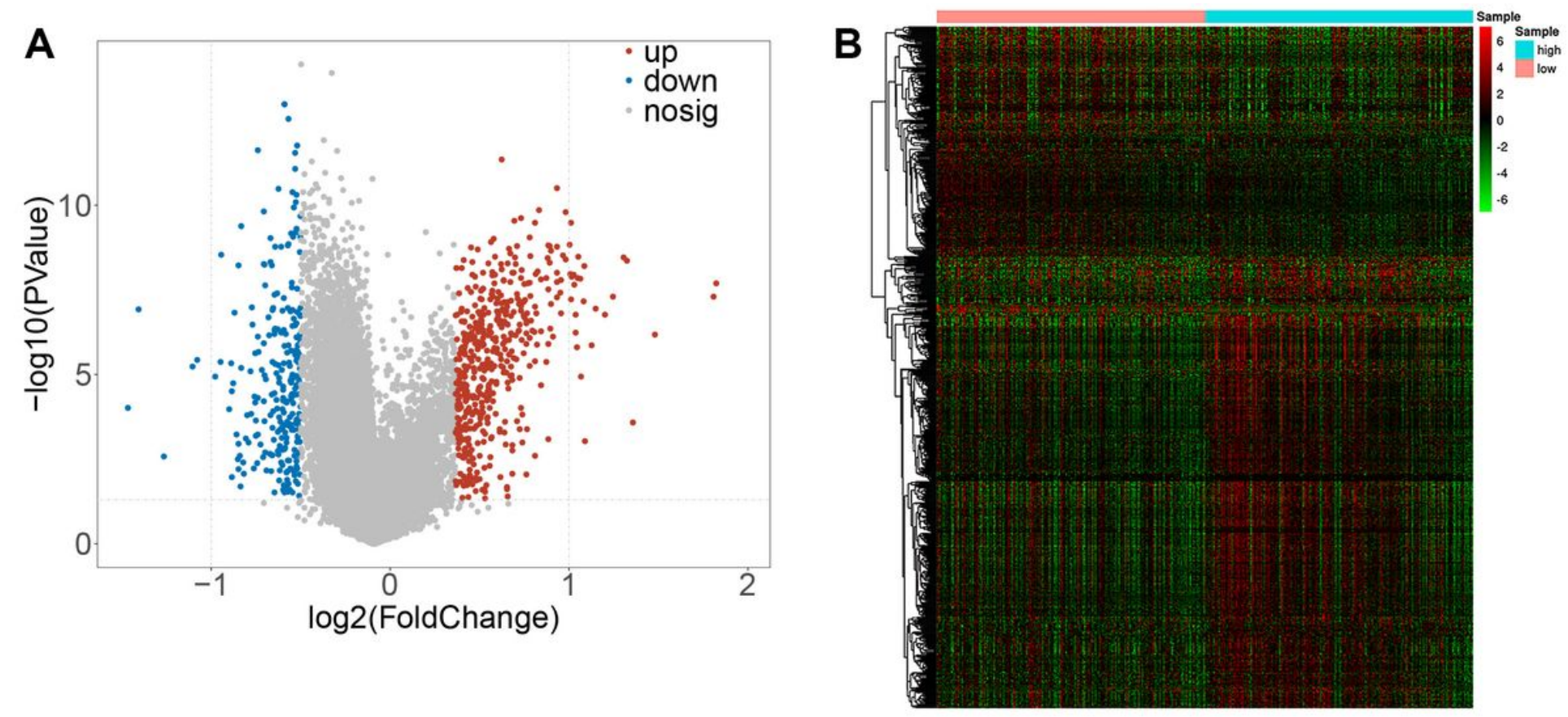

\section{Figure 8}

Identification of the DEGs between high-risk score group and low-risk score group in BC. A The volcano plot of DEGs between high-risk and low-risk groups in bladder cancer. B The heatmap of DEGs between high-risk and low-risk groups in bladder cancer. 

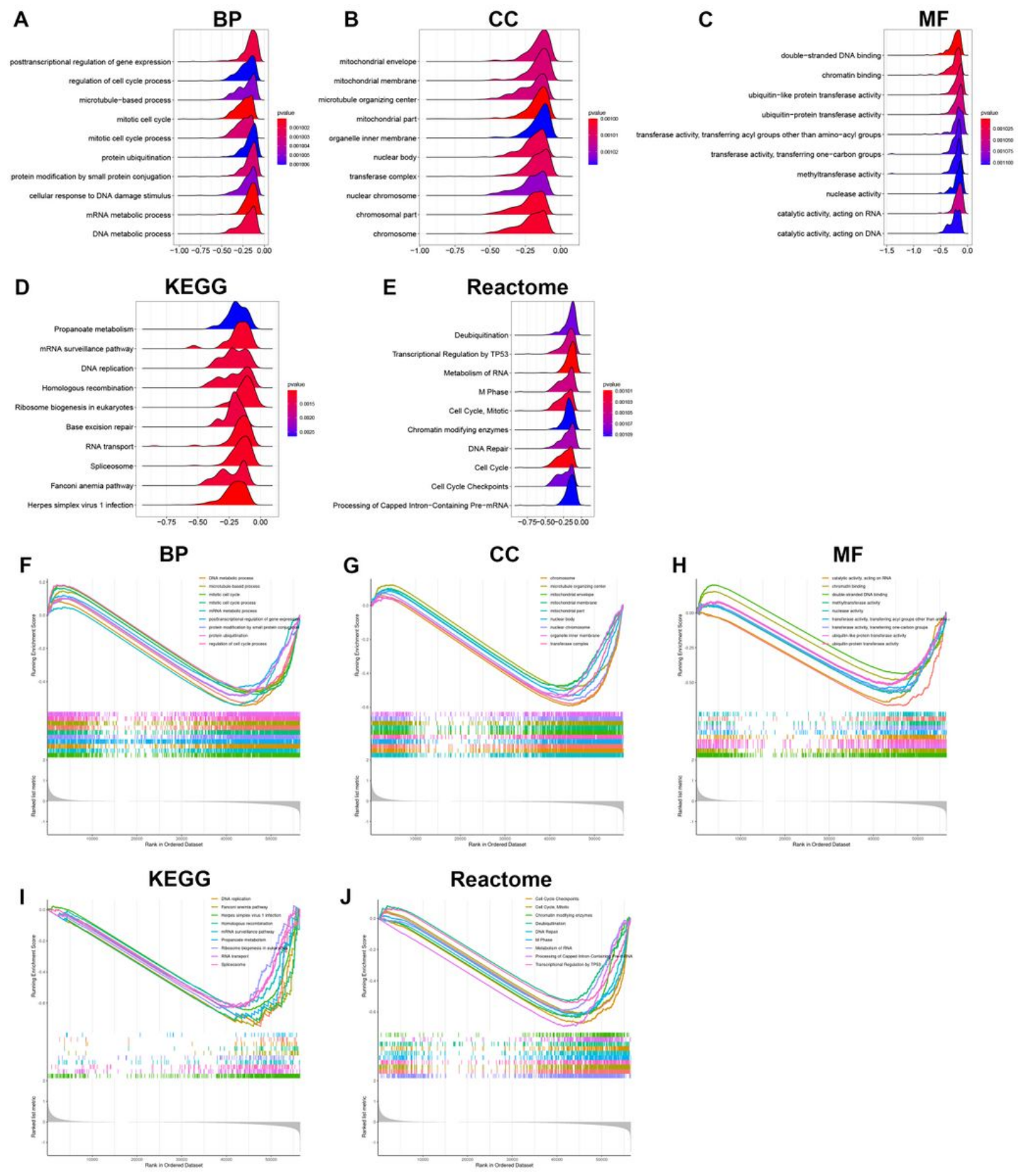

\section{Figure 9}

Function analysis of the risk score-related DEGs in BC. A-E The peak diagrams of GO annotation, KEGG and Reactome pathways enrichment by GSEA, respectively. F-J The ridge line graphs of GO annotation, KEGG and Reactome pathways enrichment by GSEA, respectively.

\section{Supplementary Files}

This is a list of supplementary files associated with this preprint. Click to download.

- SupplementaryFig.1.rar

- Supplementarytablels.rar 